Int. J. Dev. Biol. 60: 127-139 (2016)

doi: $10.1387 / \mathrm{ijdb} .150400$ tc

\title{
Alterations to retinal architecture prior to photoreceptor loss in a mouse model of retinitis pigmentosa
}

\author{
SARAH L. ROCHE, ALICE C. WYSE-JACKSON, ASHLEIGH M. BYRNE, ANA M. RUIZ-LOPEZ \\ and THOMAS G. COTTER* \\ Cell Development and Disease Laboratory, Biochemistry Department, Biosciences Institute, \\ University College Cork, Cork, Ireland
}

\begin{abstract}
Mouse models of retinitis pigmentosa (RP) are essential tools in the pursuit to understand fully what cell types and processes underlie the degeneration observed in RP. Knowledge of these processes is required if we are to develop successful therapies to treat this currently incurable disease. We have used the rd10 mouse model of RP to study retinal morphology prior to photoreceptor loss, using immunohistochemistry and confocal microscopy on cryosections, since little is known about how the mutation affects the retina during this period. We report novel findings that the mutation in the rd10 mouse results in retinal abnormalities earlier than was previously thought. Defects in rod and cone outer segments, bipolar cells, amacrine cells and photoreceptor synapses were apparent in the retina during early stages of postnatal retinal development and prior to the loss of photoreceptors. Additionally, we observed a dramatic response of glial cells during this period. Microglia responded as early as postnatal day (P) $5 ; \sim 13$ days before any photoreceptor loss is detected with Müller glia and astrocytes exhibiting changes from P10 and P15 respectively. Overall, these findings present pathological aspects to the postnatal development of the rd10 retina, contributing significantly to our understanding of disease onset and progression in the rd10 mouse and provide a valuable resource for the study of retinal dystrophies.
\end{abstract}

KEY WORDS: Pde6b, rd10, retinitis pigmentosa, postnatal retinal development, microglia

\section{Introduction}

Retinitis pigmentosa (RP) encompasses a set of hereditary diseases resulting in a progressive loss of rod and cone photoreceptors in the retina and eventual blindness. Mutations in a large variety of genes have been linked to autosomal-dominant, autosomalrecessive and X-linked RP (Hartong et al., 2006). Included in this array of genes is phosphodiesterase- $6 b$ (pde6b), mutations in which account for $4-5 \%$ of autosomal-recessive cases. Pde6b codes for cGMP-specific phosphodiesterase 6b, an essential component in the rod signal transduction pathway, triggered by photon absorption (Cote 2004; Kennan et al., 2005).

Mouse models of RP have greatly advanced our understanding of the disease. The best-characterized mouse model is the rd1 mouse, which carries a point mutation in pde6b (Pittler and Baehr 1991). Although this model has been widely used in the study of RP, the rapid loss of photoreceptors overlapping with postnatal development of the retina has resulted in limitations to its use (Carter-Dawson et al., 1978; Sanyal and Bal 1973). The development of potential treatments is difficult using this mouse model, due to the narrow time frame before onset of disease, which coincides with retinal development.

The rd10 mouse model of RP also possesses a point mutation in pde6b (Chang et al., 2002; Chang et al., 2007; Han et al., 2013). This has proven to be a suitable model for studying the course of degeneration and developing treatments, as photoreceptors are lost at a rate that closely resembles disease progression in humans. In the rd10 mouse, loss of rods is observed from postnatal day (P)18 and peaks P21 (Barhoum et al., 2008; Gargini et al., 2007; Pennesi et al., 2012; Samardzija et al., 2012). This is accompanied by morphological changes in rod and cone outer segments as

\footnotetext{
Abbreviations used in this paper: CD68, cluster of differentiation 68; GFAP, glial fibrillary acidic protein; GS, glutamine synthetase; Ibal, ionized calcium binding adaptor molecule 1; INL, inner nuclear layer; IPL, inner plexiform layer; ONL, outer nuclear layer; OPL, outer plexiform layer; P, postnatal day; Pde6b, phosphodiesterase-6b; PCNA, proliferating cell nuclear antigen; PKC $\alpha$, protein kinase $\mathrm{C}$ alpha; PNA, peanut agglutinin; RGC, retinal ganglion cell; RP, retinitis pigmentosa; TUNEL, terminal deoxynucleotidyl transferase dUTP nick end labeling.
}

\footnotetext{
*Address correspondence to: Thomas G. Cotter. Biochemistry \& Cell Biology, BioSciences Institute, University College Cork, Ireland. Tel: +353-21-490-1321. Fax: +353-21-490-1382. E-mail: t.cotter@ucc.ie
}

Accepted: 20 April 2016.

ISSN: Online 1696-3547, Print 0214-6282 
well as a loss of photoreceptor axon terminals at P20 (Barhoum et al., 2008). Therefore, the nuclear and plexiform layers in the retina have established their mature state (Caley et al., 1972) before the onset of significant photoreceptor loss. Degeneration of photoreceptors follows a clear gradient from the central to the peripheral regions of the retina, with a delay of 2-3 days observed between these regions (Gargini et al., 2007). Degeneration also occurs more rapidly in the central retina in comparison to the periphery (Barhoum et al., 2008). Similar to human RP, rods are lost first, with cones persisting into adulthood (Barhoum et al., 2008; Gargini et al., 2007).

In the rd10 retina, cells other than photoreceptors are also affected at time-points coinciding with photoreceptor loss. A shortening of horizontal cell processes, reduced bipolar cell connectivity with both the outer nuclear layer (ONL) and retinal ganglion cell (RGC) layer, as well as a reduction in the size of amacrine cell appendages were observed in the central retina at P20 (Barhoum et al., 2008; Puthussery et al., 2009). Therefore, although the primary insult is present in rods, other retinal cell types are also affected by the mutation during the course of photoreceptor degeneration.

The above studies report on retinal degeneration coinciding with photoreceptor loss in the rd10 retina. However, there is little known about retinal development in the rd10 mouse prior to the appearance of signs of photoreceptor degeneration. We know that cells respond to the mutation before any signs of degeneration in the ONL. For example, the rd10 retina presents signs of ER stress and calpain activation at P15 (Rodriguez-Muela et al., 2015). It is clear from the above studies that cell types outside the ONL are affected by the degeneration of photoreceptors. Therefore, we believe that study of the retina prior to photoreceptor loss deserves further attention, and that a more comprehensive analysis from earlier, developmental time-points is required to expand our understanding of how and when all cell types found in the retina are affected by the mutation.

A body of literature has characterized the various cell types found in the retina along with how they interact to form a complex circuit of neuronal and non-neuronal networks (Masland 2001; Masland 2012a; Masland 2012b). The fully developed retina presents itself as a highly organized structure, arranged into three nuclear layers separated by synaptic layers, known as plexiform layers. Fig. 1 illustrates the variety of cell types found in the mammalian retina and the layers they normally reside in. Six major neuronal cell types develop within the retina; rods, cones, bipolar cells, horizontal cells, amacrine cells and retinal ganglion cells, along with a single type of glial cell, the Müller glia. Two other glial cell types also reside in the retina but originate from other sources, namely astrocytes and microglia. Astrocytes arise from the brain and migrate to the retina through the optic nerve (Vecino et al., 2015). Müller glia and astrocytes are considered the macroglia of the retina and are neuron-supporting glial cells. Microglia are the resident macrophages, which migrate in to the retina from other sources in the central nervous system (Cuadros and Navascues 1998; Vecino et al., 2015).

In the current study, we sought to provide a comprehensive analysis of development and degeneration in the rd10 retina from P5, studying a variety of cell types. To our knowledge, the rd10 retina has not been studied so early on in development. The results of this study highlight a novel finding that rod photoreceptor outer segments begin to display abnormalities from P10 in the central retina. In support of the current literature documenting changes in bipolar cells, amacrine cells and horizontal cells as a consequence of the mutation in rods, we confirm that these changes are present but at earlier stages than was previously thought. Surprisingly and of significant interest, we show that microglia respond to the mutation from as early as P5, with Müller glia eliciting a response from $\mathrm{P} 10$. This study highlights for the first time, the presence of cellular alterations in the rd10 retina from P5. These changes were observed in a variety of retinal cell types. This study consequently furthers our understanding of the disease and should be considered when trialing potential treatments for RP using this mouse model.
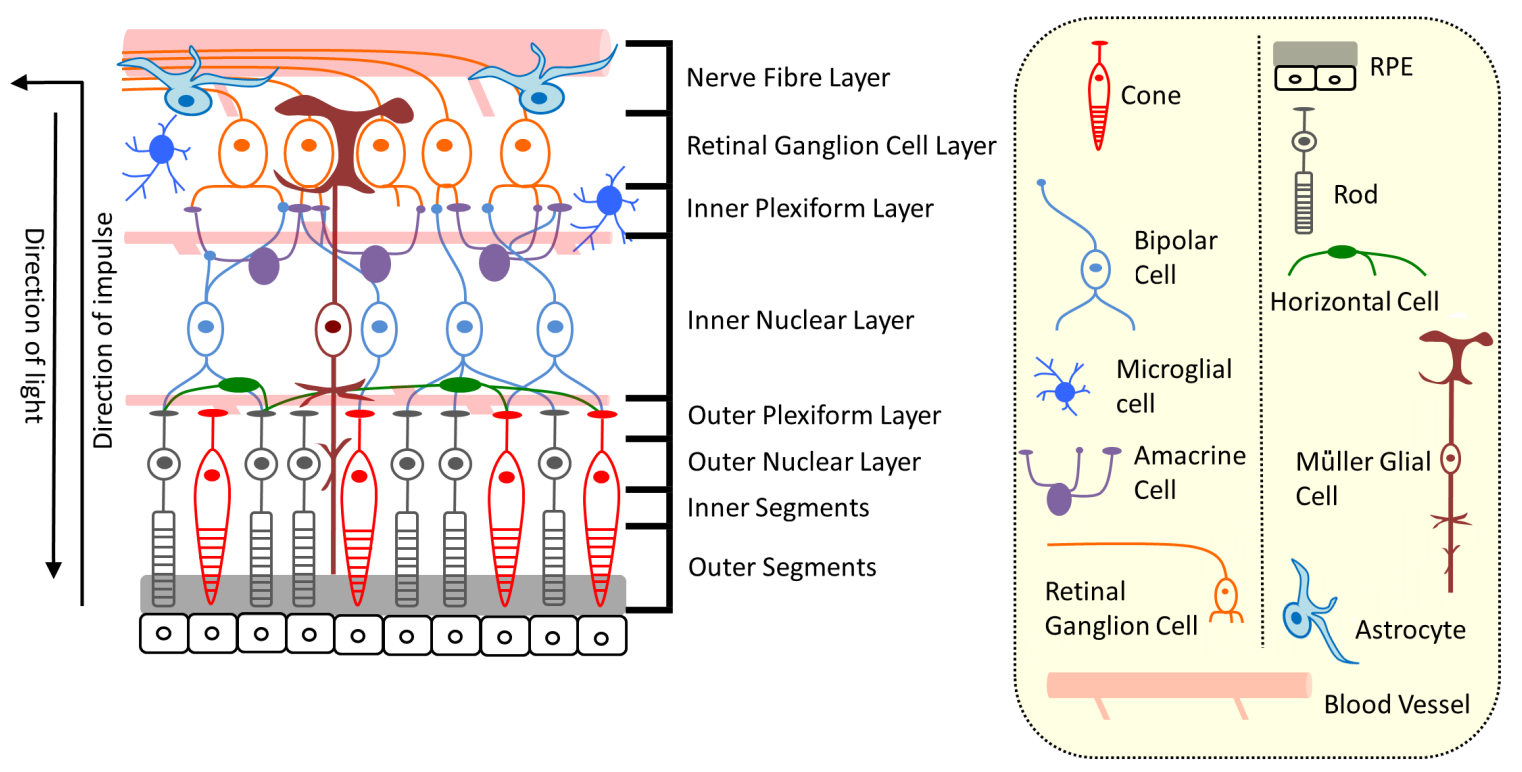

Fig. 1. Simplified schematic of the fully developed mouse retina, illustrating the variety of cell types and connections found in the retina. 


\section{Results}

\section{Rods and cones}

In support of previous publications, we observed extensive loss of central and peripheral photoreceptors in the rd10 retina at P20 compared to age-matched control mice (Fig. 2 A,B) (Barhoum et al., 2008). Terminal deoxynucleotidyl transferase dUTP nick end labeling (TUNEL) analysis revealed the presence of dying cells in the ONL from P15 in the central (Fig. 2A) and P20 in the peripheral retina (Fig. 2B). Measurement of ONL thickness confirmed a significant loss of photoreceptors from P20 in the central and peripheral rd10 retina (Fig. 2C). Previously undocumented, analysis of photoreceptor outer segments from P5 - P25 revealed defects at early time points. Rhodopsin immunolabeling revealed sparse rod outer segments from P10 in the rd10 central retina (Fig. $3 A)$. In the peripheral retina, rod outer segment morphology was abnormal from P15, suggesting a central to peripheral gradient in rod outer segment defects (Fig. 3B). Cone outer segments, identified by peanut agglutinin (PNA) displayed similar abnormalities from $\mathrm{P} 15$ in the central (Fig. $3 \mathrm{~A}$ ) and $\mathrm{P} 20$ in the peripheral rd10 retina (Fig. 3B). Measurement of outer segment length confirmed a significant loss in rod and cone outer segments from P10 and P15 in the central retina (Fig. $3 C$ ) and P15 and P20 in the peripheral retina respectively (Fig. 3D). These novel findings suggest that photoreceptor outer segments are abnormal prior to any loss of photoreceptors in the rd10 retina.

\section{Inner nuclear layer}

Due to the initial appearance of outer segment abnormalities in the central retina, we chose to focus on this region in our analyses of other cell types that might also be affected by the mutation in pde6b. Morphology of cells in the inner nuclear layer (INL) of the retina also showed abnormalities in the rd10 mouse at early developmental time points compared to control. Two markers were used to assess bipolar cell morphology. Visualization of $\mathrm{CHX10}$, a marker of bipolar cell bodies, revealed normal quantities and localization of bipolar cells in the rd10 mouse from P5 - P20 (Fig. 4A). A significant loss in $\mathrm{CHX10}$ immunoreactivity was evident at P25 in the rd10 retina, suggesting a loss of bipolar cells following the loss of photoreceptors (Fig. $4 \mathrm{~A}, \mathrm{~B}(\mathrm{i})$ ). This was supported by a significant decrease in INL thickness at P25 in the rd10 retina (Fig. 4C). Detection of protein kinase $\mathrm{C}$ alpha (PKC $\alpha$ ) was used
A

A Central retina

P5

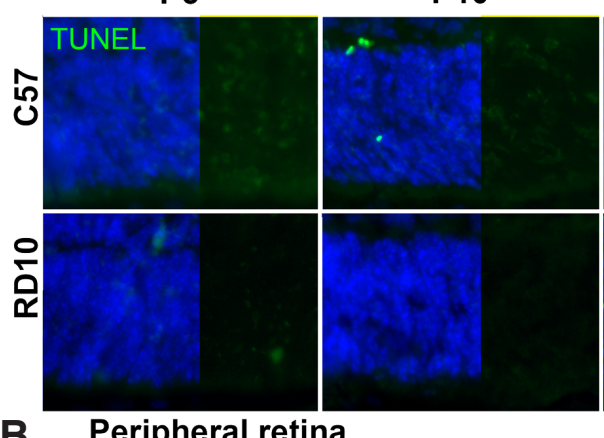

\section{B Peripheral retina}

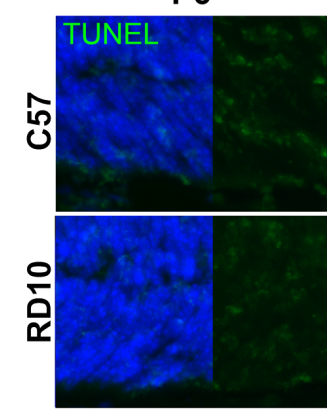

C (i) P5

P10

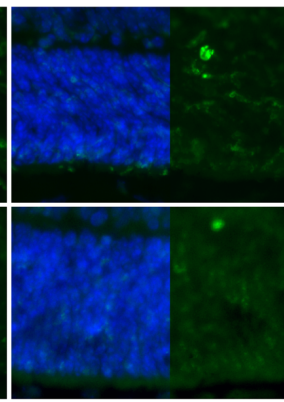

C57

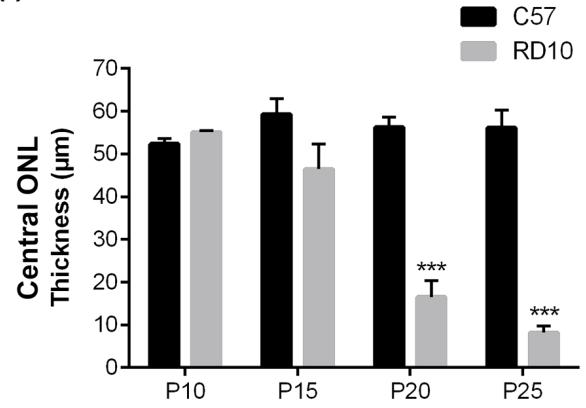

P15

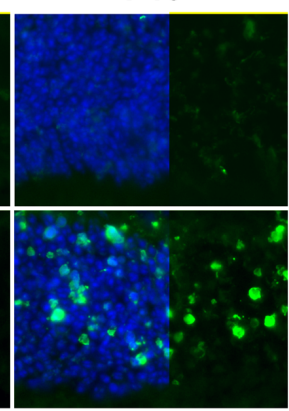

P20

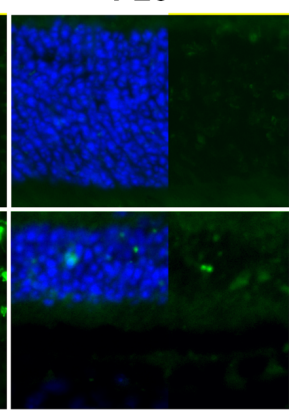

P20

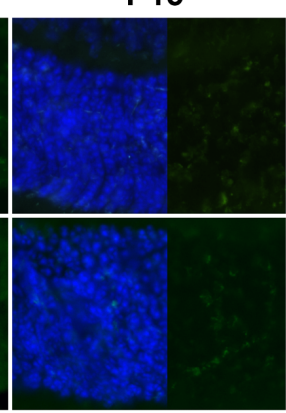

(ii)
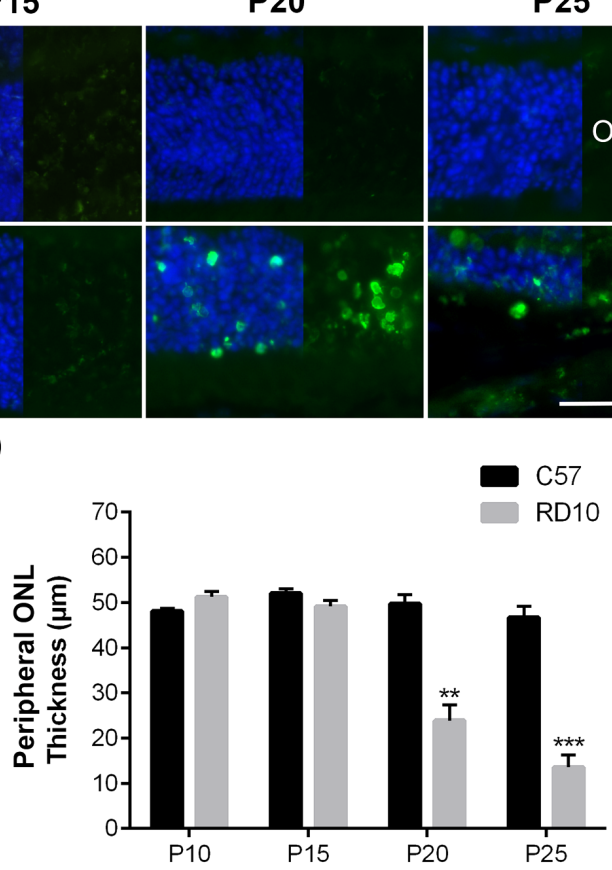

P25

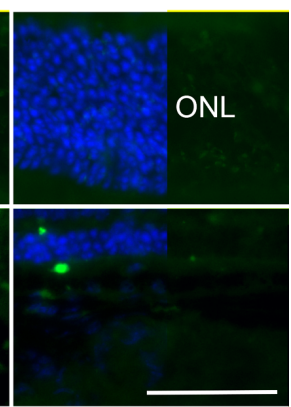

P25

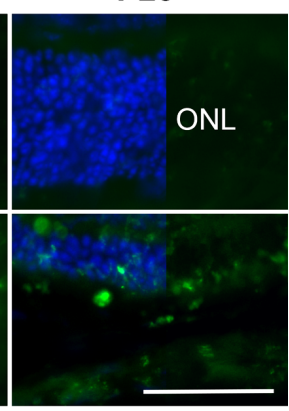

57 10 


\section{A Central retina}

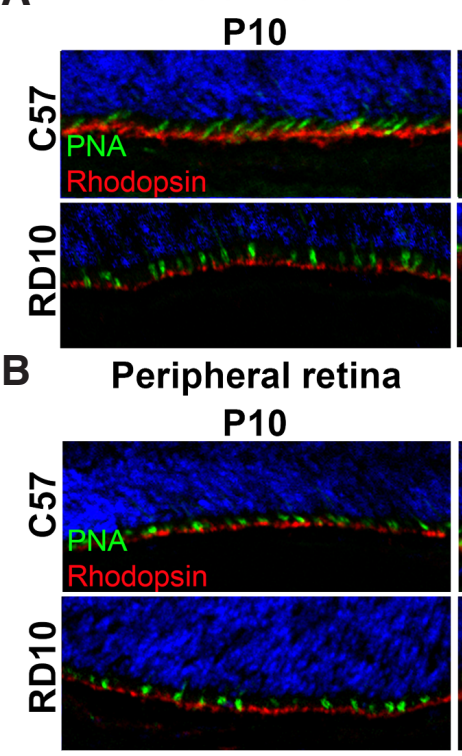

C (i)

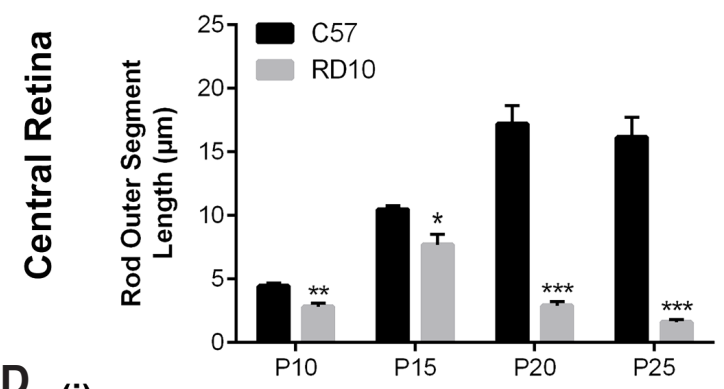

D (i)

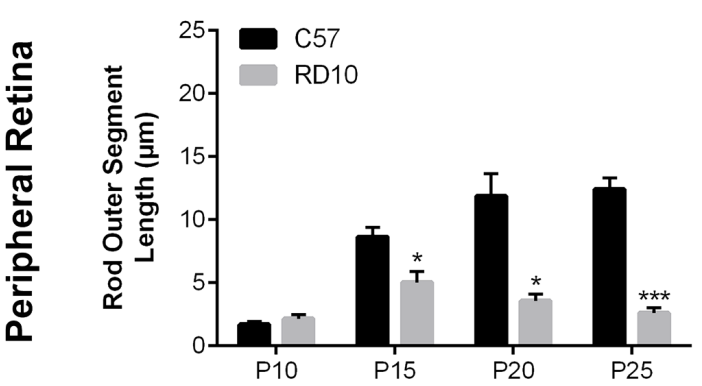

P15

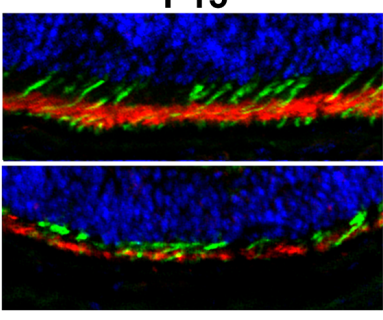

P15

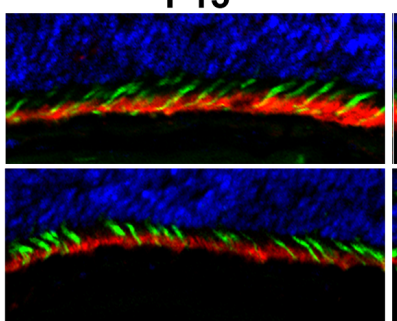

(ii)
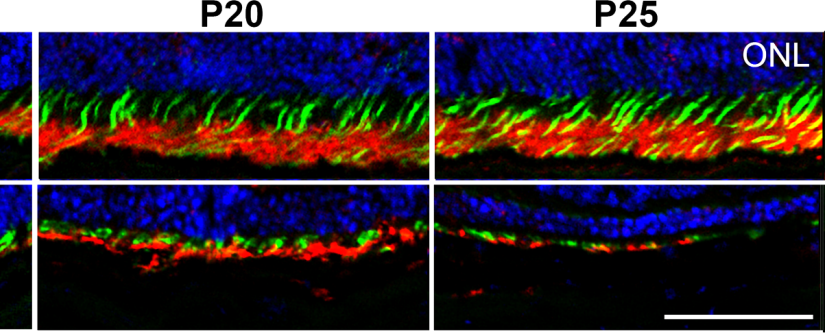

P25

20

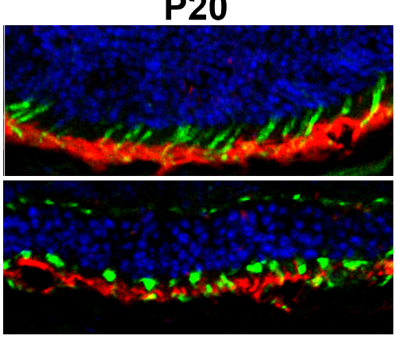

P25
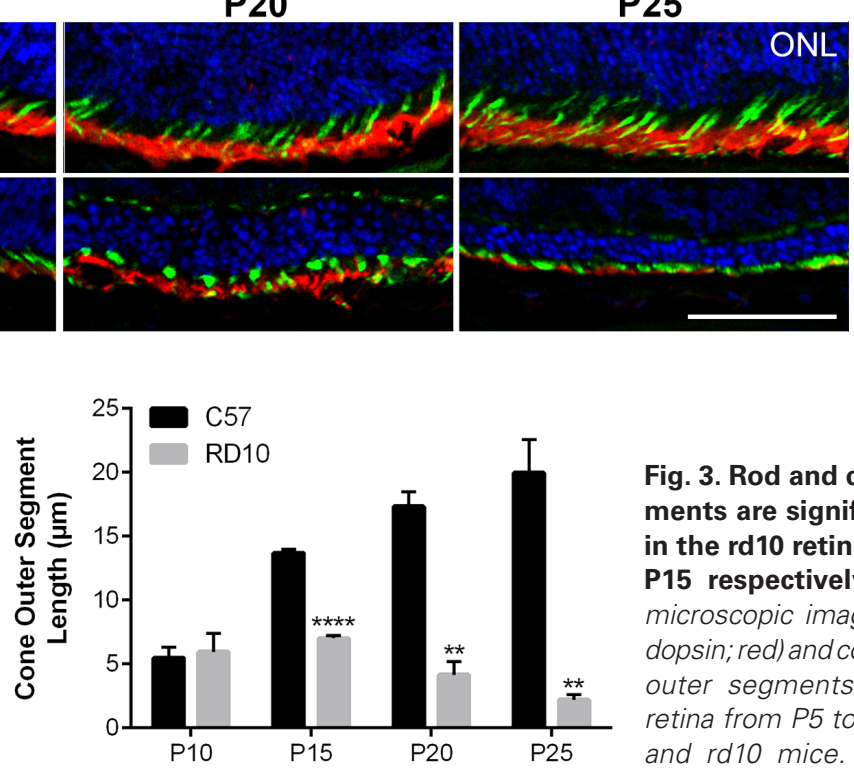

(ii)

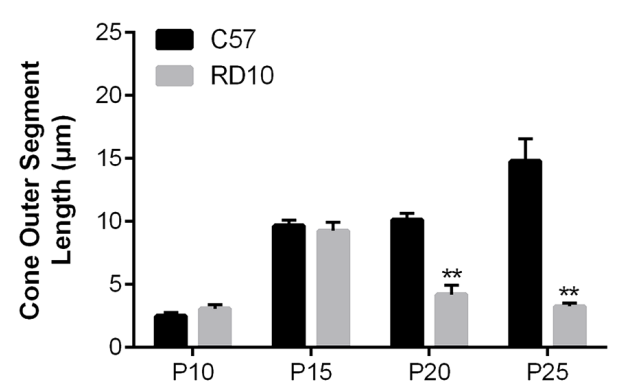

Fig. 3. Rod and cone outer segments are significantly shorter in the rd10 retina from $\mathrm{P} 10$ and P15 respectively. (A) Confocal microscopic images of rod (rhodopsin; red) and cone (PNA; green) outer segments in the central retina from $P 5$ to $P 25$ in C57BL6 and rd10 mice. Rod and cone outer segments appeared shorter from $P 10$ and $P 15$ respectively. (B) Confocal microscopic images of rod (rhodopsin; red) and cone (PNA; green) outer segments in the peripheral retina from $P 5$ to $P 25$ in C57B L6 and rd10 mice. Rod and cone outer segments appeared shorter from P15 and P20 respectively. Scale bar represents 50 um. (C,D) Quantification of (i) rod and (ii) cone outer segment length in the central (C) and peripheral (D)

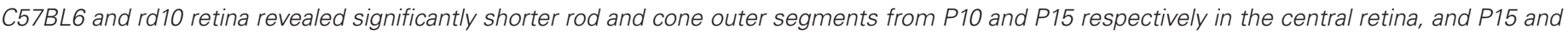

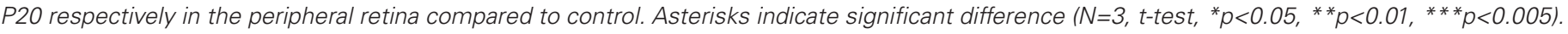

to study the extensions and terminals of rod bipolar cells. This revealed significantly less $\mathrm{PKC} \alpha$ immunoreactivity in the inner plexiform layer (IPL) and outer plexiform layer (OPL) in the rd10 retina compared to control, evident from P10 (Fig. 4 A,B(ii)).

Calbindin was used as a marker for horizontal cells. Fluorescence intensity of calbindin was significantly reduced in the rd10 retina from P15 compared to control (Fig. $5 \mathrm{~A}, \mathrm{C}(\mathrm{i})$ ). This indicates a change in horizontal cell morphology, coinciding with the onset of cell death in the ONL (Fig. 2). Amacrine cells form a dense network of synapses with RGCs (Masland 2012b), visualized by staining for syntaxin-1 in the IPL. Syntaxin-1 immunoreactivity was significantly lower from P5 in the rd10 retina compared to control (Fig. 5 B,C (ii)), suggesting reduced synaptic connectivity between amacrine cells and RGCs prior to loss of photoreceptors (Fig. 5 B,C(ii)).

\section{Outer plexiform layer}

Considering the rd10 mutation is found in rods of the ONL, we next analyzed the OPL for any abnormalities in pre-synaptic connectivity between the photoreceptors and cells of the INL. Synaptic connections were assessed by visualizing levels of synaptophysin. Significantly less synaptophysin immunoreactivity was present in the rd10 retina from P5 compared to control (Fig. 6 A,B). This suggests that synaptic connectivity between the ONL and INL is reduced prior to any loss of photoreceptors in the rd10 retina. 


\section{Macroglia}

Müller glia and astrocytes were studied by visualizing glutamine synthetase (GS) and glial fibrillary acidic protein (GFAP). These cells are considered the macroglia of the retina. GFAP, a cytoskeletal protein, is highly expressed in astrocytes but is also expressed in Müller glia in conditions of retinal insult (Grosche et al., 1995; Lewis and Fisher 2003; Xue et al., 2006). GS converts glutamate to glutamine and was used as a marker for Müller glia. There was a significant decrease in GS immunoreactivity from P10 - P20 in the rd10 retina compared to control (Fig. 7 A,C(i)). GFAP immunoreactivity revealed increased expression in the RGC layer in the rd10 retina from P15 (Fig. 7 A,C(ii)). GFAP is known to be expressed in Müller glia and astrocytes (Chen and Weber 2002). GFAP was found co-localized with GS in the Müller glial endfeet (Fig. 7B; yellow) as well as in regions of the RGC layer where GS was not present (Fig. 7B; arrows) suggesting that both Müller glia and astrocytes are responsible for the increased expression of GFAP in the rd10 retina.

\section{Microglia}

Microglial number and phagocytic activity were assessed using markers for ionized calcium binding adaptor molecule 1 (Iba-1) and cluster of differentiation (CD68) respectively. Surprisingly, a significant increase in the number of microglia was observed as early as $\mathrm{P} 5$ in the rd10 retina compared to control, in the RGC layer and IPL (Fig. $8 \mathrm{~A}, \mathrm{C}(\mathrm{i})$ ). CD68 immunoreactivity was also higher in the rd10 microglia at P5 (Fig. 8A). This novel finding indicates the presence of a microglial response to the mutation in pde6b at least 13 days before photoreceptor loss at P18. The number of microglia in the RGC layer and IPL remained significantly higher at P10 in the rd10 retina (Fig. $8 \mathrm{~A}, \mathrm{C}(\mathrm{i})$ ). At $\mathrm{P} 15$ increased numbers of $\mathrm{CD}^{+} 8^{+}$microglia were observed in the rd10 retina, in the photoreceptor layer (Fig. $8 \mathrm{~A}, \mathrm{~B}, \mathrm{C}(\mathrm{ii}))$. Increased numbers of microglia were present in the rd10 retina at P20 and P25 (Fig. $8 \mathrm{~A}, \mathrm{C}$ ) and were highly reactive for CD68 (Fig. 8A). In order to determine if increased numbers of microglia in the rd10 retina were due to proliferation within the retina, immunoreactivity of proliferating cell nuclear antigen (PCNA) in microglia was analyzed. In the control retina at P5, proliferating microglia were rarely observed, whereas high numbers of proliferating microglia were found in the rd10 RGC layer (Fig. $\left.9 ;{ }^{*}\right)$. Similar numbers of proliferating microglia were observed in both the $\mathrm{C} 57$ and rd10 mice at P10 (Fig. 9, $\left.{ }^{*}\right)$. As shown in Fig. 8, microglia were scarce at P15 in the C57 retina. In contrast, high numbers of microglia were found in the rd10 retina, close to the ONL in the particular, and appeared to be proliferating (Fig. 9). These results suggest that proliferation of microglia within the retina contributes, at least in part, to increased numbers of microglia in the rd10 retina.

\section{Discussion}

In this study we present findings that retinal architecture in rd10 mice
C

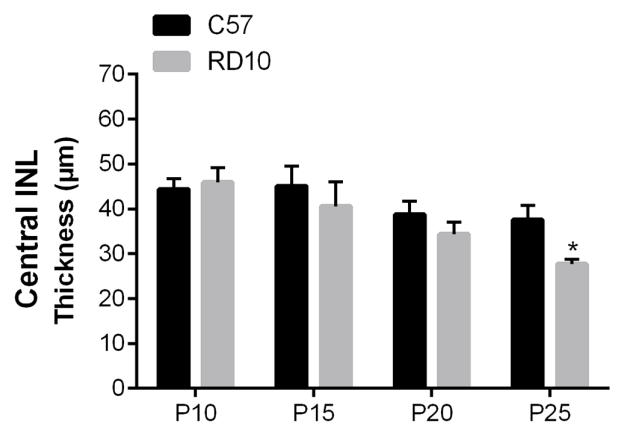

Fig. 4. Bipolar cells display significant changes in their synaptic connections from P10 and are lost from P25 in the rd10 central retina. (A) Confocal microscopic images of bipolar cell bodies (CHX10; green) and extensions (PKC-alpha; red) in the central retina from P5 to P25 in C57BL6 and rd10 mice displayed a decrease in PKC-alpha immunoreactivity from P10 in the rd10 retina, in both the IPL and OPL (*). CHX10 immunoreactivity was decreased from P20 in the $\mathrm{rd} 10$ retina. Scale bar represents $50 \mu \mathrm{m}$. (B) Quantification of fluorescence intensity revealed significant decreases in $\mathrm{CHX} 10$ and PKC-alpha immunoreactivity in the rd10 retina from $\mathrm{P} 25$ and P10 respectively compared to control. (C) Quantification of INL thickness revealed a significant decrease in the rd10 retina at $P 25$ compared to control. Asterisks indicate significant difference $\left(N=3\right.$, t-test $\left.,{ }^{*} p<0.05,{ }^{*} p<0.01,{ }^{* *} p<0.005\right)$. 
A

Horizontal cells

P5

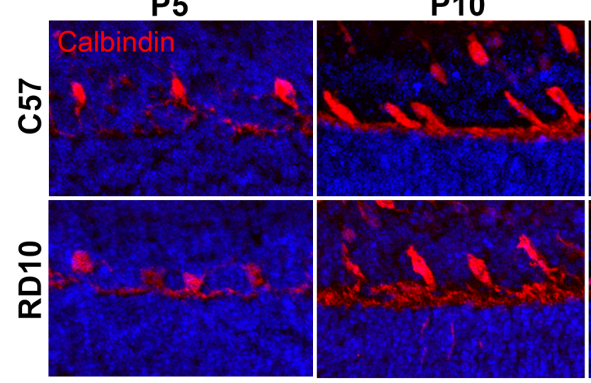

B

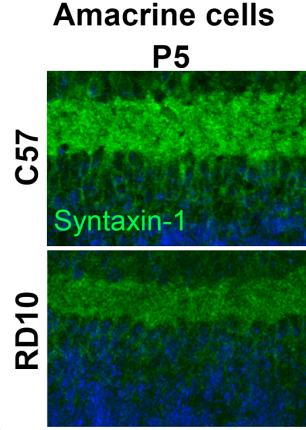

C

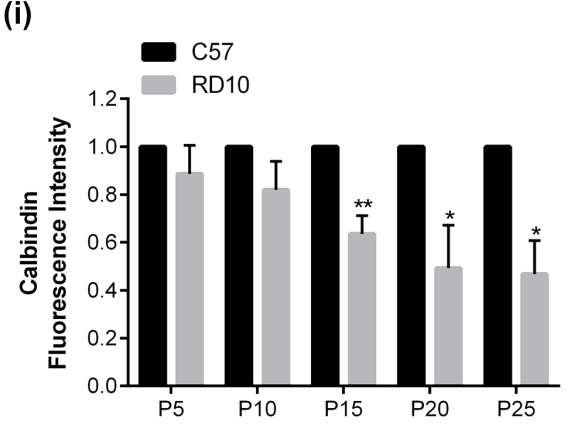

P15

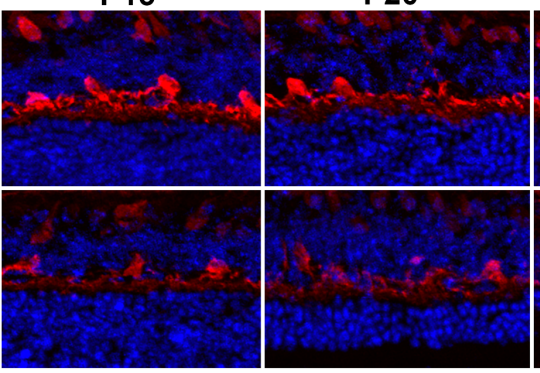

P15

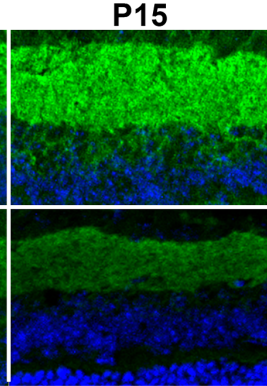

(ii)

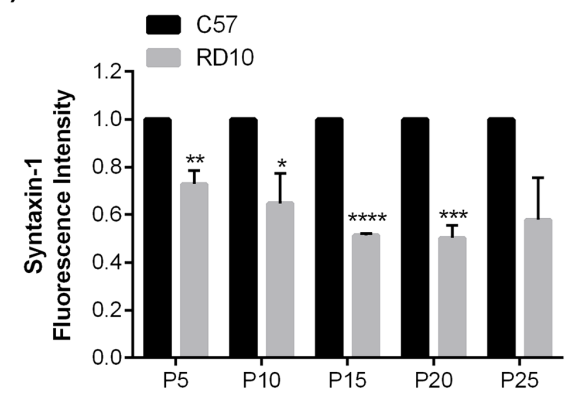

P25

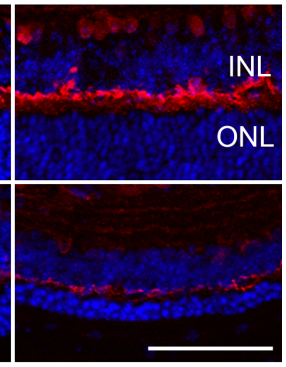

P25

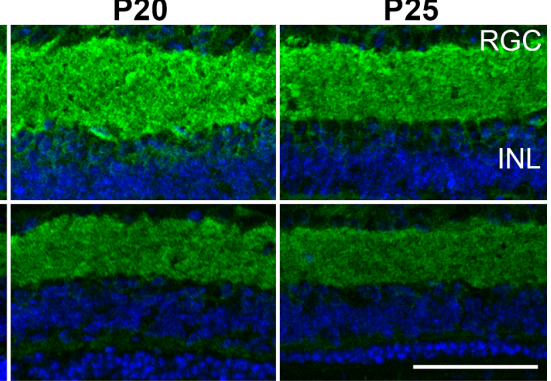

INL

Fig. 5. Horizontal cells and amacrine cells display significant changes in their morphology from P15 and P5 respectively in the rd10 central retina. (A) Confocal microscopic images of horizontal cells (calbindin; red) in the central retina from P5 to P25 in C57BL6 and rd10 mice displayed a decrease in calbindin immunoreactivity from $P 15$ in the rd10 retina. Scale bar represents 50um. (B) Confocal microscopic images of amacrine cells (syntaxin-1; green) in the central retina from P5 to P25 in C57BL6 and rd10 mice revealed a decrease in syntaxin-1 immunoreactivity from P5 in the rd10 retina. Scale bar represents $50 \mu \mathrm{m}$. (C) Quantification of fluorescence intensity revealed significant decreases in calbindin and syntaxin-1 immunoreactivity in the rd10 retina from $P 15$ and $P 5$ respectively compared to control. Asterisks indicate significant difference $\left(N=3, t\right.$-test, ${ }^{*} p<0.05$, $\left.{ }^{* *} p<0.01,{ }^{* *} p<0.005\right)$.

\section{A Outer plexiform layer synapses}

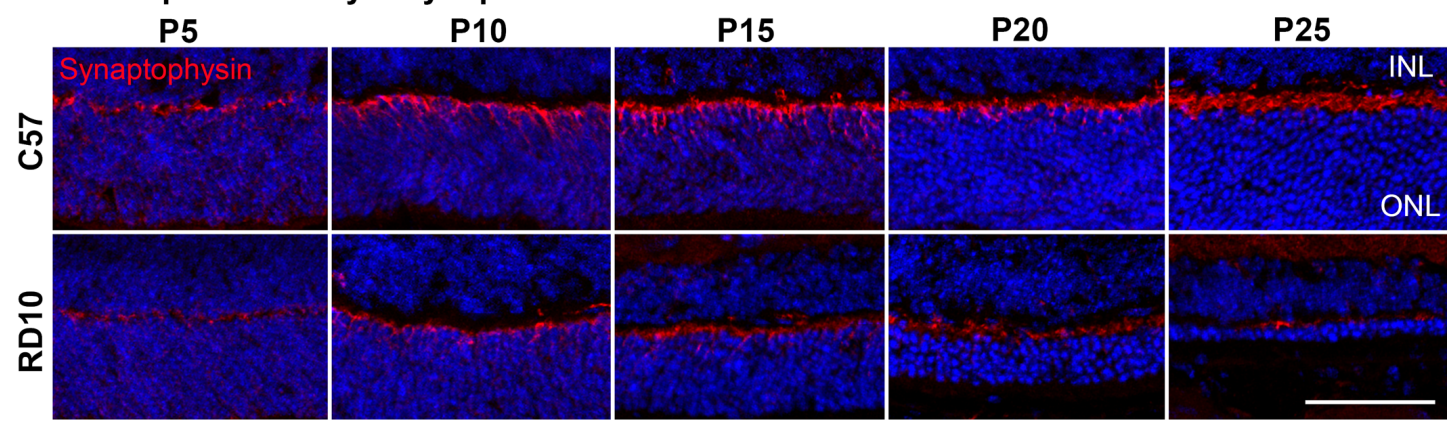

B

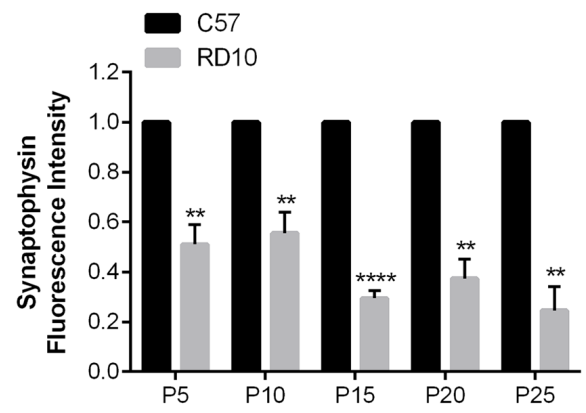

Fig. 6. Pre-synapses in the OPL display alterations from P5 in the rd10 central retina. (A) Confocal microscopic images of pre-synapses in the OPL (synaptophysin; red) in the central retina from P5 to P25 in C57BL6 and rd10 mice revealed a decrease in synaptophysin immunoreactivity from P5 in the rd10 retina. Scale bar represents 50 um. (B) Quantification of fluorescence intensity revealed a significant decrease in synaptophysin immunoreactivity in the rd10 retina from $P 5$ compared to control. Asterisks indicate significant difference $(N=3$, t-test, $\left.{ }^{*} p<0.05,{ }^{*} p<0.01,{ }^{*}{ }^{*} p<0.005\right)$. 
undergoes alterations from as early as $\mathrm{P} 5 ;$ 13 days before photoreceptor loss begins. We also provide a comprehensive analysis of markers for various cell types that, to our knowledge, have not yet been studied in the rd10 mouse at such early time-points. Our results demonstrate that a variety of cell types are affected by the mutation in pde6b prior to any loss of photoreceptors. This is an important finding in the context of potential treatments for $\mathrm{RP}$, as it suggests that treatments might need to target a variety of cell types and at an early pre-symptomatic stage.

\section{Rods and cones}

It has previously been shown that rod outer segments display morphological abnormalities at $\mathrm{P} 20$ in the rd10 retina (Barhoum et al., 2008). Our results showing a disruption to rod outer seg- ments in the central retina from $\mathrm{P} 10$, presents a novel finding that rods are affected by the mutation earlier than was previously shown (Fig. 3). We observed abnormal rod outer segments in the peripheral retina from P15, which agrees with the documented central to peripheral gradient of degeneration in the rd10 retina (Gargini et al., 2007). Cone outer segments remained unaffected in the central retina until $\mathrm{P} 15$ and in the peripheral retina until P20 (Fig. 3), in support of studies detailing changes in cones later than rods in RP mouse models (Barhoum et al., 2008; Gargini et al., 2007). Pre-synaptic connectivity between photoreceptors and INL cells exhibited abnormal morphology from P5 (Fig. 6). These results indicate that one of the earliest structural changes of photoreceptors in response to the mutation, is in synaptic connectivity with cells in the INL, followed by alterations in outer

\section{A Macroglia}

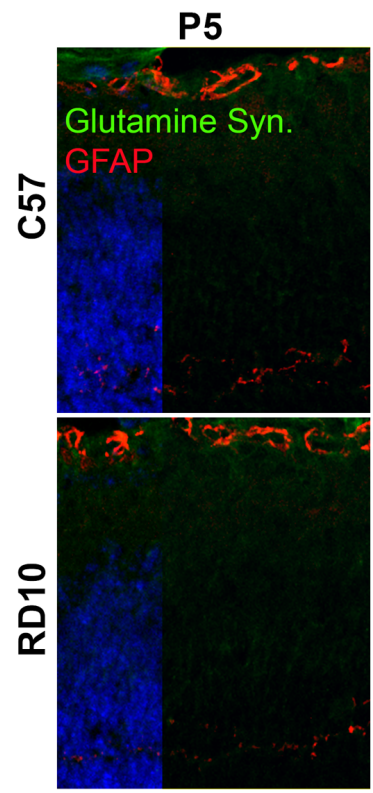

B

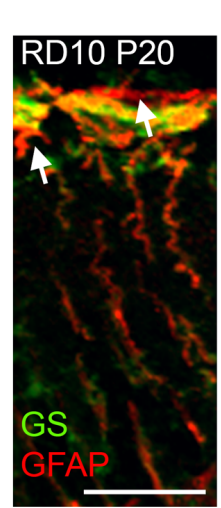

(i)
P10
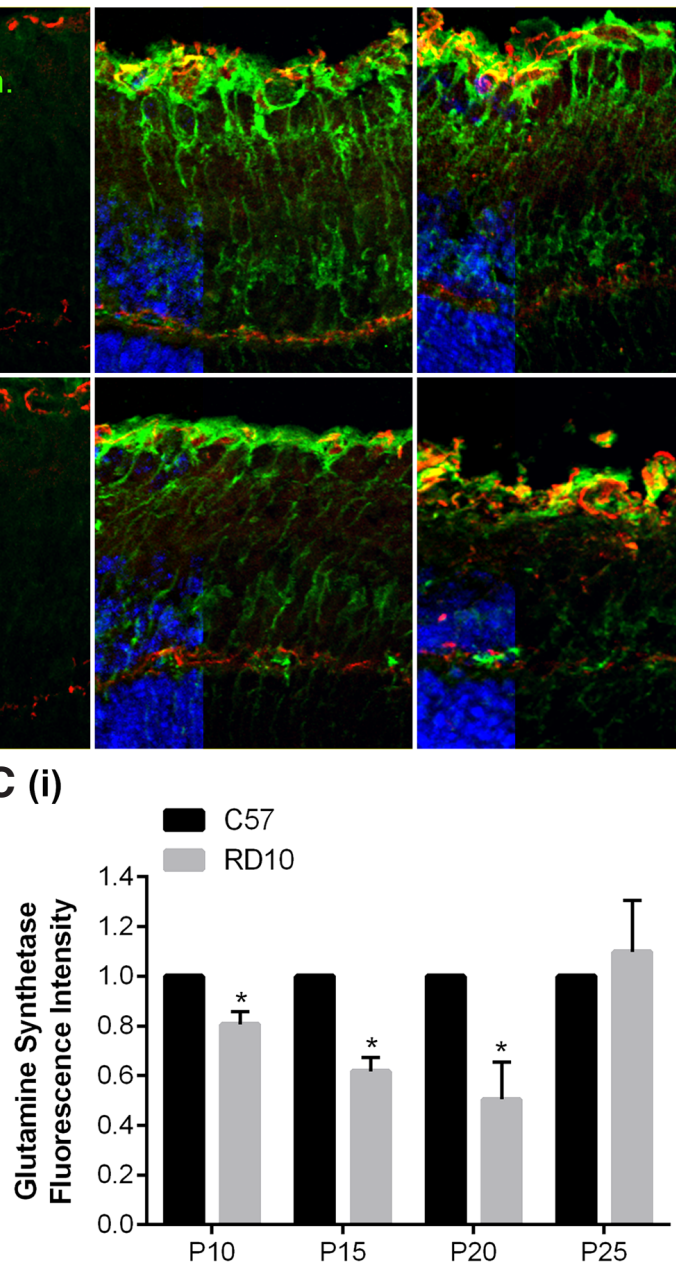

P20
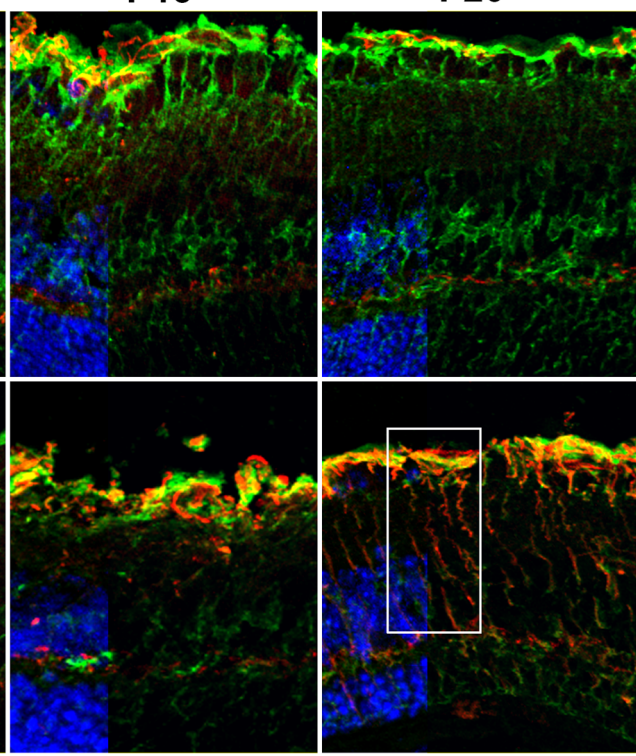

(ii)

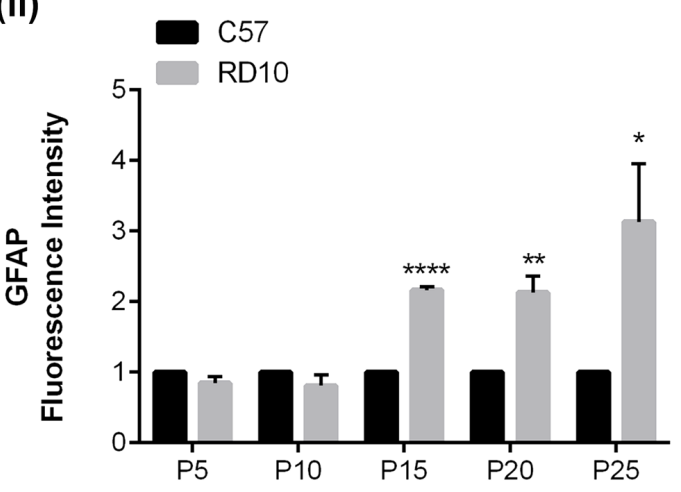

Fig. 7. Changes in Müller glial and astrocytic activity are present from P10 and P15 respectively in the rd10 central retina. (A) Confocal microscopic images of Müller glia (glutamine synthetase (GS); green) and GFAP (red) in the central retina from P5 to P25 in C57BL6 and rd10 mice revealed a decrease in GS immunoreactivity from P10 and an increase in GFAP immunoreactivity from P15 in the rd10 retina. Scale bar represents 50 um. (B) Confocal microscopic images of GS (green) and GFAP (red) immunoreactivity in the central retina of P20 rd10 retinas revealed high levels of co-localization in the RGC layer (yellow). Areas of GFAP immunoreactivity negative for GS staining were also evident (red; arrowheads), indicating GFAP immunoreactivity in astrocytes. Scale bar represents $25 \mu \mathrm{m}$. (C) Quantification of fluorescence intensity revealed a significant decrease in GS immunoreactivity from P10 (i) and a significant increase in GFAP immunoreactivity from P15 (ii) in the rd10 retina compared to control. Asterisks indicate significant difference $\left(N=3\right.$, t-test, $\left.{ }^{*} p<0.05,{ }^{*} p<0.01,{ }^{* * *} p<0.005\right)$. 
A Microglia

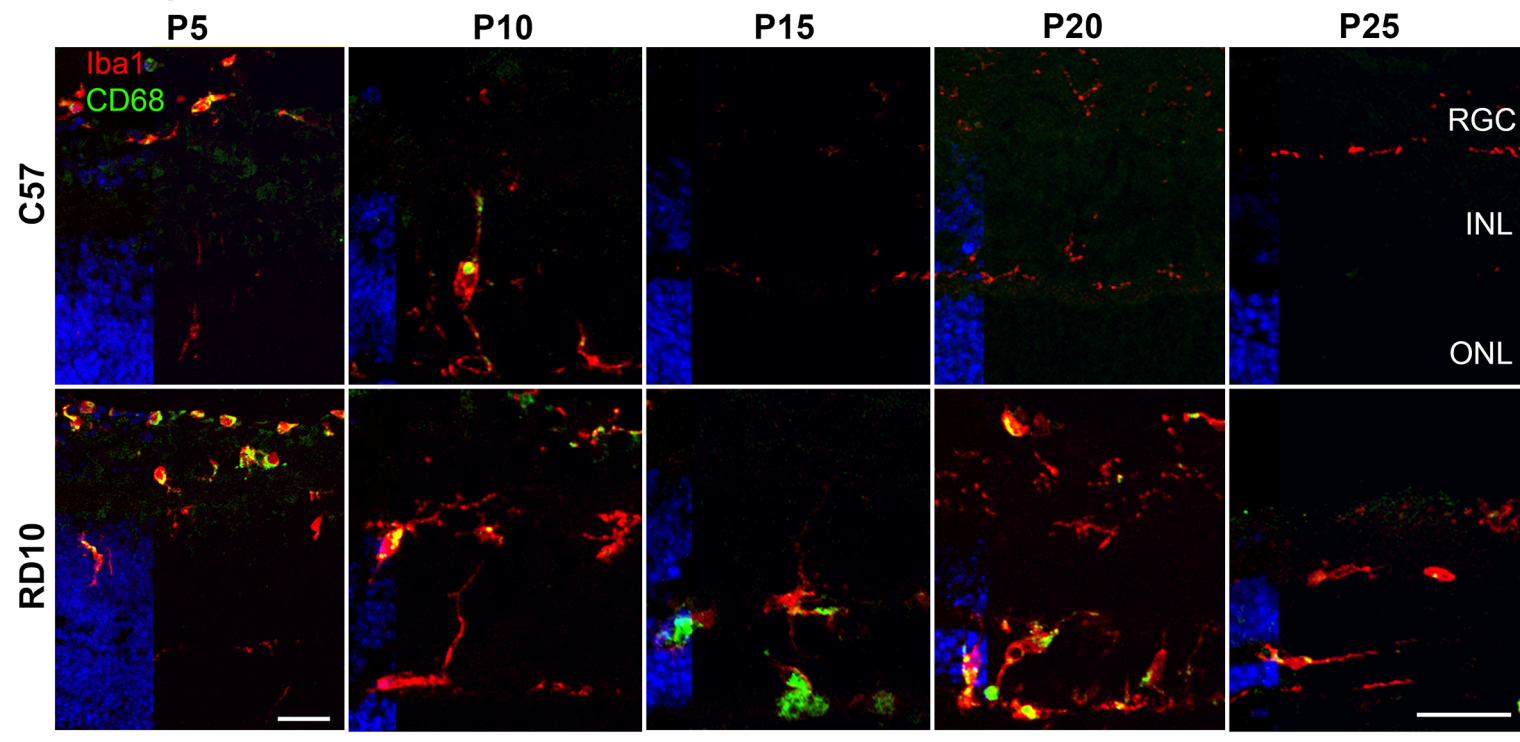

B
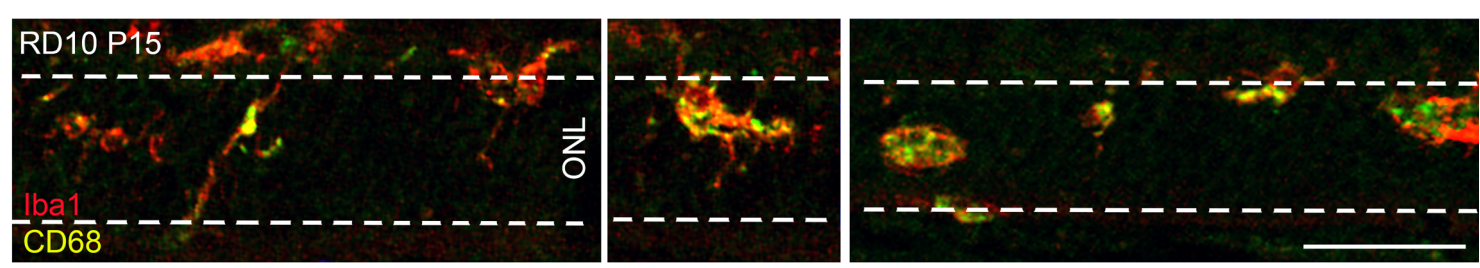

C (i)

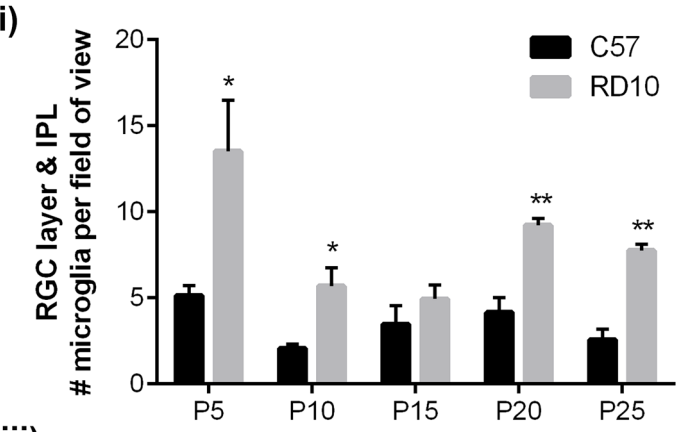

(iii)

(ii)

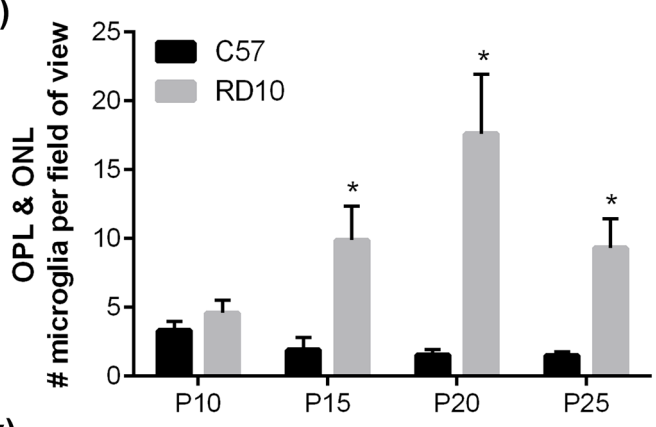

(iv)
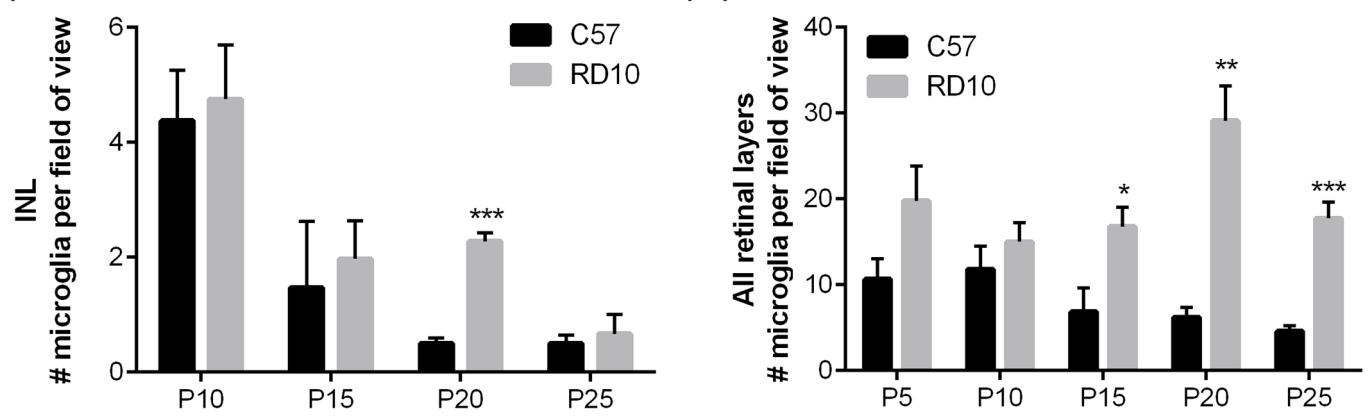

Fig. 8. Microglia respond to the mutated rods as early as P5 in the rd10 central retina. (A) Confocal microscopic images of microglia (Iba-1; red and CD68; green) in the central retina from P5 to P25 in C57BL6 and rd10 mice revealed increased numbers of reactive microglia at P5 in the RGC layer. High numbers of reactive microglia were present in the rd10 ONL at P15 and P20. Scale bar represents 50 $\mu$ m. (B) Confocal microscopic images of microglia (Iba-1; red and CD68; green) in the central retina at P15 show phagocytic microglia in the rd10 ONL. Scale bar represents 50 um. (C) Quantification of microglial numbers revealed significantly more microglia from P5 in the RGC layer and IPL in the rd10 retina compared to control (i). Significantly more microglia were present in the rd10 INL at P20 (ii) and OPL \& ONL at P15 (iii) compared to control. Numbers of microglia in the retina inclusive of all layers were significantly higher in the rd10 retina from P15 compared to control (iv). Asterisks indicate significant difference ( $N=3, t$-test, $\left.{ }^{*} p<0.05,{ }^{*} p<0.01,{ }^{* * *} p<0.005\right)$. 
segments and eventual photoreceptor cell loss.

\section{Inner nuclear layer}

Changes in INL cells, coinciding with photoreceptor cell loss have previously been documented in the rd10 retina. A shortening of horizontal cell processes, reduced bipolar cell connectivity with both the ONL and RGC layer, as well as a reduction in the size of amacrine cell appendages, were observed in the central retina at P20 (Barhoum et al., 2008; Puthussery et al., 2009). Our analysis of INL cells in the central retina highlighted an early effect of the mutation on second-order neurons, before the loss of photoreceptors (Figs. 4 and 5). Changes to bipolar and amacrine cell morphology was noticeable prior to degeneration of the ONL. Bipolar cells were lost from P25 whilst their synaptic connections were noticeably sparser from P10 in the central retina. Amacrine cell synapses with RGCs appeared less dense from P5. Although surprising, these early changes in second-order neurons were not completely unexpected as it has previously been shown that structural changes became evident in rod bipolar cells and horizontal cells prior to photoreceptor loss in the Royal College of Surgeons rat (RCS), a model of RP (Cuenca et al., 2005). Similar to early alterations present in photoreceptors, our analyses on INL cells suggest that synaptic connectivity between cells of the INL and other cell layers is altered prior to any loss of photoreceptors.

\section{Macroglia}

Astrocytes normally reside in the RGC layer, in close association with the vasculature via astrocytic processes (Bussow 1980). Our studies revealed an increase in GFAP levels in astrocytes of the rd10 retina (Fig. 7), which is indicative of reactive gliosis (Pekny and Lane 2007; Pekny and Nilsson 2005). This could lead to the formation of a glial scar that can inhibit proper functioning of the surrounding tissue (Fawcett and Asher 1999), as inhibition of reactive gliosis in damaged retinas has been shown to be neuroprotective (Ganesh and Chintala 2011).

Müller glia, the predominant glial cell type in the retina, are specialized radial glia that span the entire depth of the retina and contact all neurons and their processes as well as capillary networks (Vecino et al., 2015). These glial cells are essential for maintaining retinal structure and homeostasis in the healthy retina, and providing trophic support in disease states (Bringmann et al., 2009; Bringmann et al., 2006; Joly et al., 2008; Newman and Reichenbach 1996; Vecino et al., 2015). Postmitotic Müller glia also retain the remarkable ability to dedifferentiate into other retinal cell types (Blackshaw et al., 2004; Fischer and Reh 2001; Ooto et al., 2004; Singhal et al., 2012). Our results clearly show that Müller glia upregulate GFAP and downregulate GS from P10 in the rd10 retina (Fig. 7). A similar result was observed in a light damage model of retinal degeneration (Grosche et al., 1995) and is a sign of Müller cell gliosis (Belecky-Adams et al., 2013). In the rd10 mouse, it is possible that Müller glia are attempting to dedifferentiate, in response to pathological changes taking place in the retina. Interestingly, Müller glia attempting to dedifferentiate in the adult rd10 retina has already been suggested by studies on the transcriptome (Uren et al., 2014). Our study adds to this, suggesting that Müller glial cells attempt to dedifferentiate during the initial stages of degeneration in the rd10 retina. It has already been shown that an upregulation of cytoskeletal proteins and downregulation of GS is associated with activated porcine Müller glia in culture (Hauck et al., 2003). In addition, decreased levels of GS in the Müller glial somata were observed following optic nerve crush (Chen and Weber 2002), which was interpreted as Müller glia initiating dedifferentiation in an attempt to replace dying cells. A reduction in GS could be additive to the already stressful environment in the $\mathrm{rd10}$, as GS is known to be neuroprotective against retinal insult (Gorovits et al., 1997).
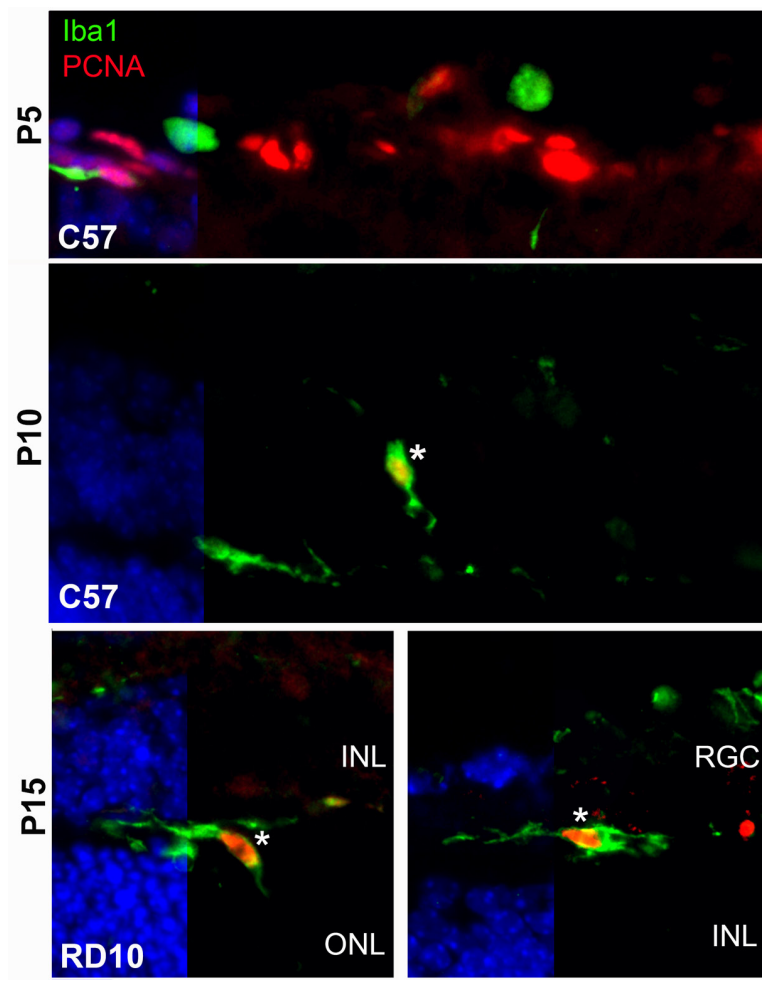

NL
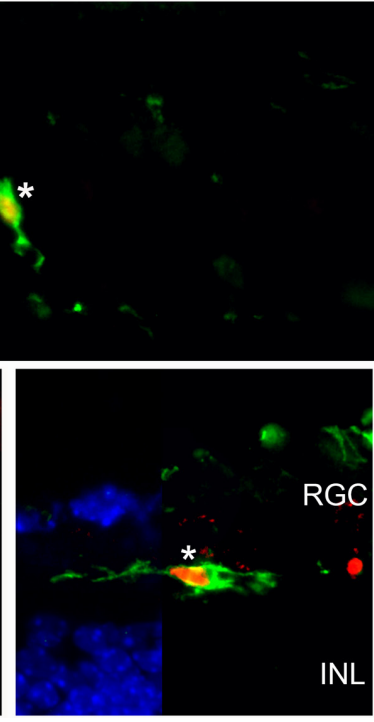

INL
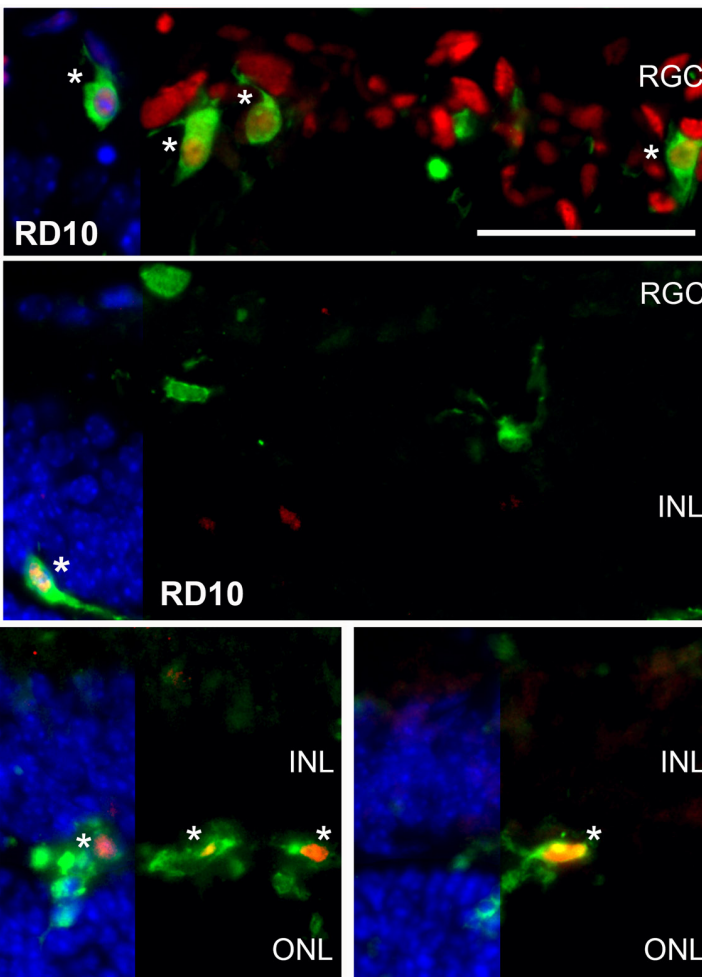

INL

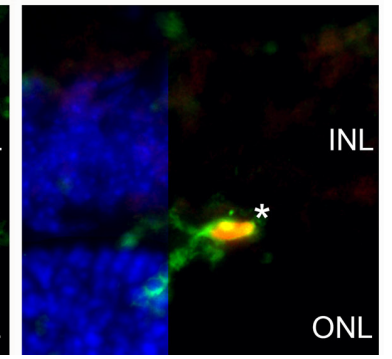

Fig. 9. Microglia proliferate within the rd 10 retina from P5. Increased numbers of proliferating microglia (*; Iba1 \& PCNA-positive) were observed in the $r d 10$ retina at P5 and P15 compared to control. Proliferating microglia were rarely observed in the $\mathrm{C57}$ retina. Scale bar represents $50 \mathrm{um}$. 


\section{Microglia}

A surprising result from our analysis was observed in the microglia. Microglia are normally found close to the RGC layer and IPL (Santos et al., 2008), surveying and responding to the environment in normal and disease states (Hanisch and Kettenmann 2007; Kreutzberg 1996; Langmann 2007). They are essential in the clearance of unwanted debris left behind from dead cells (Egensperger et al., 1996). We have shown that microglia respond to the mutated rods as early as P5, by proliferating and changing to an activated phenotype (Figs. 8 and 9 ). It is becoming increasingly clear that microglia play an important role in both the healthy and degenerating retina (Karlstetter et al., 2010; Vecino et al., 2015), and may serve as a therapeutic target in treating RP (Yoshida et al., 2013; Zhao et al., 2015). The current literature presents a two-sided story on the role of microglia in disease states. Microglia appear to play beneficial as well as detrimental roles during retinal degeneration (Arroba et al., 2011; Langmann 2007), which likely depends on the severity of the insult (Lai and Todd 2008).

In support of the notion that microglial activity promotes photoreceptor survival under stressful conditions are studies showing that microglia-derived trophic support protects photoreceptors in vivo (Harada et al., 2002) and in vitro during light-induced degeneration (Wang etal., 2011). In the rd10 retina, depletion of microglial progenitor cells accelerates photoreceptor death (Sasahara et al., 2008), whilst depleting resident microglia attenuates insulin-like growth factor 1-mediated photoreceptor protection (Arroba et al., 2011).

In contrast, there is a body of literature supporting the idea that microglial activation precedes and possibly contributes to damage and cell death in the retina. One such study showed that media conditioned by activated microglia induces photoreceptor cell death in vitro, using $661 \mathrm{~W}$ cells (Roque et al., 1999). In the rd10 mouse it has recently been shown that depleting microglia as well as inhibiting microglial phagocytosis resulted in increased protection of mutated photoreceptors (Zhao et al., 2015). It has also been shown in other mouse models of RP that NADPH oxidase activation in microglia resulted in rod cell death (Zeng et al., 2014) and inhibition of reactive gliosis prevents apoptosis of retinal neurons and provides neuroprotection (Ganesh and Chintala 2011; Peng et al., 2014). Interestingly, we also know that increased levels of reactive oxygen species are found in the ONL of rd10 retinas (Bhatt et al., 2010), potentially due to activated microglia. Collectively, these studies enforce the notion that the microglial response to injured photoreceptors can be a harmful and fatal one.

Our results clearly show that microglia respond to the mutation in pde6b 13 days before photoreceptor loss (Fig. 8). Although this has never before been documented in the rd10 retina, it is not surprising considering a similar response of microglia has been observed in other models of photoreceptor degeneration and insult (Harada et al., 2002; Noailles et al., 2014; Roque et al., 1996; Santos et al., 2010; Thanos 1992; Wang et al., 2014). In the rd mouse model of RP, microglial activation also preceded photoreceptor loss (Zeng et al., 2005) and microglia appeared to migrate from the RGC layer to the ONL, possibly in response to chemokine production by the diseased photoreceptors (Zeng et al., 2005).

An interesting observation in the rd10 retina was that upon reaching the ONL, microglia extend their processes throughout the photoreceptors, intimately contacting clusters of cells (Fig. 8 $A, B)$. The presence of activated microglial cells in affected regions together with photoreceptor degeneration prompts the notion of microglial-driven degeneration. It is possible that microglia are attempting to save dying photoreceptors. However, based on the aforementioned literature, it may also be the case that this close interaction between cell types is part of the cascade of cell death that ensues a few days later. One such possibility is that microglia are exposing the photoreceptors to stressful stimuli, such as reactive oxygen species or inflammatory mediators. This could lead to oxidative stress in the ONL (Zeng et al., 2014) and subsequent apoptosis (Carmody and Cotter 2000; Carmody et al., 1999), as photoreceptors are highly sensitive to changes in oxygen levels (Wellard et al., 2005). In support of this, anti-oxidants and antiinflammatories have been shown to slow photoreceptor cell death in rd10 mice (Komeima et al., 2007; Peng et al., 2014). Future studies will therefore be aimed at further understanding the role that microglia play in the course of degeneration in the rd10 retina.

In this study, we showcase the novel finding that substantial modifications in retinal architecture are present from as early as P5 in the rd10 retina, during stages of early postnatal retinal development. Abnormalities in photoreceptor outer segments and synapses, bipolar cells and amacrine cells are apparent prior to the loss of photoreceptors. These findings highlight the presence of a developmental pathology in the rd10 mice, whereby various cells of the retina undergo morphological modifications in response to the mutation in pde6b during a period of postnatal development. In addition, we observed significant responses of Müller glia, astrocytes and microglia during this time, with microglia eliciting a response from P5. These findings consequently deepen our understanding of the disease and thus will need to be considered when designing potential treatments. Future studies will be aimed at providing more detailed and mechanistic insight in to the role that glial cells play in the course of degeneration in the rd10 retina, with a particular focus on whether or not microglia could be a driving force behind the enormity of cell death associated with RP.

\section{Materials and Methods}

\section{Animals}

All animals were maintained and handled in accordance with the Association for Research in Vision and Ophthalmology statement for the Use of Animals in Ophthalmic and Vision Research. Homozygous rd10/rd10 mice (B6.CXBI-Pde6hrd10/J) were obtained from the Jackson Laboratory (Bar Harbour, ME, USA). C57BL6/J wild-type mice were used as controls.

TABLE 1

\section{USED FOR IMMUNOFLUORESCENCE ON RETINAL SECTIONS}

\begin{tabular}{llll} 
Primary Antibody /Lectin & Used to identify & Species \& Dilution & Source \\
\hline Rhodopsin & Rod Outer Segments & Rb, 1:200 & Millipore \\
TRITC-PNA & Cone Outer Segments & Lectin, 1:500 & Vector Labs. \\
CHX10 & Bipolar Cells & Gt, 1:100 & Santa Cruz \\
PKC- $\alpha$ & Bipolar Cells & Rb, 1:100 & Santa Cruz \\
Calbindin & Horizontal Cells & Rb, 1:500 & Swant \\
Syntaxin-1 & Amacrine Cells & Rb, 1:500 & Millipore \\
Synaptophysin & Pre-synapses & Ms, 1:500 & Millipore \\
GFAP & Astroctyes & Rb, 1:300 & DAKO \\
Glutamine Synth. & Müller glia & Ms, 1:100 & Millipore \\
Iba-1 & Microglia & Rb, 1:500 & Wako \\
Iba-1 & Microglia & Gt, $1: 400$ & Novus Bio \\
CD68 & Microglia & Rat, $1: 500$ & AbD Serotec \\
PCNA & Proliferating cells & Rb, 1:800 & Cell Signaling \\
\hline
\end{tabular}


Mice were supplied by the Biological Services Unit, University College Cork and were humanely euthanized by cervical dislocation.

\section{Immunofluorescence on retinal sections}

Immunofluorescence on retinal sections was carried out as previously described (Wyse Jackson et al., 2016; Byrne et al., 2016). Eyes were enucleated and fixed at room temperature in $4 \%$ paraformaldehyde for $1.5 \mathrm{hr}$. Following washes, eyes were cryo-protected in $15 \%$ sucrose in 1xPBS for $1 \mathrm{hr}, 20 \%$ sucrose for $1.5 \mathrm{hr}$ and $30 \%$ sucrose overnight, all at $4^{\circ} \mathrm{C}$. Eyes were submerged and frozen in cryochrome (Thermo Scientific) and sectioned on a cryostat (Leica). Sections $(7 \mu \mathrm{m})$ were collected and stored at $-80^{\circ} \mathrm{C}$. Sections were blocked in $5 \%$ donkey serum in 1 XPBS for $30 \mathrm{~min}$ and incubated with primary antibody diluted in 5\% donkey serum overnight at $4^{\circ} \mathrm{C}$. Table 1 lists the details of all primary antibodies used. Following washes, sections were incubated with secondary antibody (Alexa Fluor donkey anti-mouse/rabbit/goat with either a 488 or 594 fluorescent probe; Molecular Probes \&/or TRITC -PNA (Vector Labs.)) for $1 \mathrm{hr}$ at room temperature. Eliminating the primary antibody in solution served as a negative control. Sections were mounted using Mowiol (Sigma) with anti-fade agent (Dabco; Sigma).

\section{Terminal dUTP nick-end labeling (TUNEL) of fragmented DNA}

DNA strand breaks in retinal cell nuclei were detected by terminal dUTP nick end-labeling (TUNEL) on fixed tissue as previously described (Wyse Jackson and Cotter 2016). Frozen retinal sections were permeabilzed with $0.1 \%$ Triton $X$ for 2 min followed by incubation with terminal deoxynucleotidyl transferase (M1875) (Promega, Kilkenny, Ireland) and fluorescein-12-dUTP (\#11373242910) (Roche, Lewes, UK) according to manufacturer's instructions. Nuclei were counterstained with Hoechst $33342(1 \mu \mathrm{g} / \mathrm{mL})($ Sigma). Sections were incubated at $37^{\circ} \mathrm{C}$ for $1 \mathrm{~h}$ in a humidified chamber and following several washes in 1 xPBS, were mounted in Mowiol. Sections were viewed under a fluorescence microscope (Leica DM LB2). For each treatment on mice, at least three animals were used and two fields ( $x 40$ magnification) per section of at least three different sections were evaluated.

\section{Microscopy}

Sections were viewed using a Leica DM LB2 microscope with a Nikon Digital Sight DS-U2 camera. Images were taken at 40x using the software NIS-Elements version 3.0, Nikon, Japan. Confocal micrographs were taken using an Olympus Fluoview FV1000 laser scanning confocal microscope, using a 20x objective. Images were taken using the software Olympus Fluoview Ver $4.1 \mathrm{a}$ and are represented as maximum intensity projections from acquisition of z-stacks. Results are representative of at least three individual mice of the same strain and age. Identical microscope settings were used when visualizing specific markers in both mouse strains and at each time-point.

\section{Quantification from immunohistochemically-labeled sections}

Quantification of ONL thickness, INL thickness and outer segment length in retinal sections was carried out using ImageJ software. Average ONL and INL thickness was measured by taking measurements from at least 20 sections per mouse. Per section, three distinct measurements were taken and averaged. Average outer segment length was measured by taking measurements from at least four sections per mouse. Per section, three distinct measurements of rod or cone outer segment length were taken and averaged. Fluorescence intensity measurements of $\mathrm{CHX} 10, \mathrm{PKC} \alpha$, calbindin, syntaxin-1, synaptophysin, glutamine synthetase and GFAP were carried out using ImageJ software on images taken from the same region and in the same orientation, at 40x magnification. These images were used to create plot profiles of the marker of interest and the area under the curve was measured as a readout of fluorescence intensity. This is a previously established method for such quantification (Irannejad et al., 2013). Number of microglia was quantified by visualizing retinal sections on a fluorescence microscope and quantifying from $40 x$ fields of views. Only microglia in which the nucleus was observed were counted.

\section{Statistical analysis}

Data were statistically analyzed using student t-test (Graph Pad, Prism 6 ) with values of $p<0.05$ being considered statistically significant. Graphical results are represented as mean \pm standard error of the mean (SEM). Results are representative of at least three individual mice of the same genotype and age.

\section{Acknowledgements}

The authors would like to express thanks to the staff of the Biological Services Unit, UCC for breeding and caring for the animals used in this study. We would also like to thank Ms Jennifer Moloney for her helpful comments and advice.

\section{References}

ARROBA, A.I., ALVAREZ-LINDO, N., VAN ROOIJEN, N. and DE LA ROSA, E.J. (2011). Microglia-mediated IGF-I neuroprotection in the rd10 mouse model of retinitis pigmentosa. Invest Ophthalmol Vis Sci 52: 9124-9130.

BARHOUM, R., MARTINEZ-NAVARRETE, G., CORROCHANO, S., GERMAIN, F., FERNANDEZ-SANCHEZ, L., DE LAROSA, E.J., DE LA VILLA, P. and CUENCA, $N$. (2008). Functional and structural modifications during retinal degeneration in the rd10 mouse. Neuroscience 155: 698-713.

BELECKY-ADAMS, T.L., CHERNOFF, E.C., WILSON, J.M. and DHARMARAJAN, S. (2013). Reactive Muller Glia as Potential Retinal Progenitors. Neural Stem Cells - New Perspectives.

BHATT, L., GROEGER, G., MCDERMOTT, K. and COTTER, T.G. (2010). Rod and cone photoreceptor cells produce ROS in response to stress in a live retinal explant system. Mol Vis 16: 283-293.

BLACKSHAW, S., HARPAVAT, S., TRIMARCHI, J., CAI, L., HUANG, H., KUO, W.P., WEBER, G., LEE, K., FRAIOLI, R.E., CHO, S.H. et al., (2004). Genomic analysis of mouse retinal development. PLOS Biol 2: E247.

BRINGMANN, A., IANDIEV, I., PANNICKE, T., WURM, A., HOLLBORN, M., WIEDEMANN, P., OSBORNE, N.N. and REICHENBACH, A. (2009). Cellular signaling and factors involved in Muller cell gliosis: neuroprotective and detrimental effects. Prog Retin Eye Res 28: 423-451.

BRINGMANN, A., PANNICKE, T., GROSCHE, J., FRANCKE, M., WIEDEMANN, P., SKATCHKOV, S.N., OSBORNE, N.N. and REICHENBACH, A. (2006). Muller cells in the healthy and diseased retina. Prog Retin Eye Res 25: 397-424.

BUSSOW, H. (1980). The astrocytes in the retina and optic nerve head of mammals: a special glia for the ganglion cell axons. Cell Tissue Res 206: 367-378.

BYRNE, A.M., ROCHE, S.L., RUIZ-LOPEZ, A.M., JACKSON, A.C. and COTTER, T.G. (2016). The synthetic progestin norgestrel acts to increase LIF levels in the rd10 mouse model of retinitis pigmentosa. Mol Vis 22: 264-274.

CALEY, D.W., JOHNSON, C. and LIEBELT, R.A. (1972). The postnatal development of the retina in the normal and rodless CBA mouse: a light and electron microscopic study. Am J Anat 133: 179-212.

CARMODY, R.J. and COTTER, T.G. (2000). Oxidative stress induces caspaseindependent retinal apoptosis in vitro. Cell Death Differ 7: 282-291.

CARMODY, R.J., MCGOWAN, A.J. and COTTER, T.G. (1999). Reactive oxygen species as mediators of photoreceptor apoptosis in vitro. Exp Cell Res 248: 520-530.

CARTER-DAWSON, L.D., LAVAIL, M.M. and SIDMAN, R.L. (1978). Differential effect of the rd mutation on rods and cones in the mouse retina. Invest Ophthalmol Vis Sci 17: 489-498.

CHANG, B., HAWES, N.L., HURD, R.E., DAVISSON, M.T., NUSINOWITZ, S. and HECKENLIVELY, J.R. (2002). Retinal degeneration mutants in the mouse. Vision Res 42: 517-525.

CHANG, B., HAWES, N.L., PARDUE, M.T., GERMAN, A.M., HURD, R.E., DAVISSON, M.T., NUSINOWITZ, S., RENGARAJAN, K., BOYD, A.P., SIDNEY, S.S. et al., (2007). Two mouse retinal degenerations caused by missense mutations in the beta-subunit of rod cGMP phosphodiesterase gene. Vision Res 47: 624-633.

CHEN, H. and WEBER, A.J. (2002). Expression of glial fibrillary acidic protein and glutamine synthetase by Muller cells after optic nerve damage and intravitreal application of brain-derived neurotrophic factor. Glia 38: 115-125.

COTE, R.H. (2004). Characteristics of photoreceptor PDE (PDE6): similarities and differences to PDE5. Int J Impot Res 16 Suppl 1: S28-33. 
CUADROS, M.A. and NAVASCUES, J. (1998). The origin and differentiation of microglial cells during development. Prog Neurobiol 56: 173-189.

CUENCA, N., PINILLA, I., SAUVE, Y. and LUND, R. (2005). Early changes in synaptic connectivity following progressive photoreceptor degeneration in RCS rats. Eur J Neurosci 22: 1057-1072.

EGENSPERGER, R., MASLIM, J., BISTI, S., HOLLANDER, H. and STONE, J. (1996). Fate of DNA from retinal cells dying during development: uptake by microglia and macroglia (Muller cells). Brain Res Dev Brain Res 97: 1-8.

FAWCETT, J.W. and ASHER, R.A. (1999). The glial scar and central nervous system repair. Brain Res Bull 49: 377-391.

FISCHER, A.J. and REH, T.A. (2001). Muller glia are a potential source of neural regeneration in the postnatal chicken retina. Nat Neurosci 4: 247-252.

GANESH, B.S. and CHINTALA, S.K. (2011). Inhibition of reactive gliosis attenuates excitotoxicity-mediated death of retinal ganglion cells. PLoS One 6: e18305.

GARGINI, C., TERZIBASI, E., MAZZONI, F. and STRETTOI, E. (2007). Retinal organization in the retinal degeneration 10 (rd10) mutant mouse: a morphological and ERG study. J Comp Neurol 500: 222-238.

GOROVITS, R., AVIDAN, N., AVISAR, N., SHAKED, I. and VARDIMON, L. (1997). Glutamine synthetase protects against neuronal degeneration in injured retinal tissue. Proc Natl Acad Sci USA 94: 7024-7029.

GROSCHE, J., HARTIG, W. and REICHENBACH, A. (1995). Expression of glial fibrillary acidic protein (GFAP), glutamine synthetase (GS), and Bcl-2 protooncogene protein by Muller (glial) cells in retinal light damage of rats. Neurosci Lett 185: 119-122.

HAN, J., DINCULESCU, A., DAI, X., DU, W., SMITH, W.C. and PANG, J. (2013). Review: the history and role of naturally occurring mouse models with Pde6b mutations. Mol Vis 19: 2579-2589.

HANISCH, U.K. and KETTENMANN, H. (2007). Microglia: active sensor and versatile effector cells in the normal and pathologic brain. Nat Neurosci 10: 1387-1394.

HARADA, T., HARADA, C., KOHSAKA, S., WADA, E., YOSHIDA, K., OHNO, S., MAMADA, H., TANAKA, K., PARADA, L.F. and WADA, K. (2002). Microglia-Muller glia cell interactions control neurotrophic factor production during light-induced retinal degeneration. J Neurosci 22: 9228-9236.

HARTONG, D.T., BERSON, E.L. and DRYJA, T.P. (2006). Retinitis pigmentosa. Lancet 368: 1795-1809.

HAUCK, S.M., SUPPMANN, S. and UEFFING, M. (2003). Proteomic profiling of primary retinal Muller glia cells reveals a shift in expression patterns upon adaptation to in vitro conditions. Glia 44: 251-263.

IRANNEJAD, R., TOMSHINE, J.C., TOMSHINE, J.R., CHEVALIER, M., MAHONEY, J.P., STEYAERT, J., RASMUSSEN, S.G.F., SUNAHARA, R.K., EL-SAMAD, H., HUANG, B. et al., (2013). Conformational biosensors reveal GPCR signalling from endosomes. Nature 495: 534-538.

JOLY, S., LANGE, C., THIERSCH, M., SAMARDZIJA, M. and GRIMM, C. (2008) Leukemia inhibitory factor extends the lifespan of injured photoreceptors in vivo. J Neurosci 28: 13765-13774.

KARLSTETTER, M., EBERT, S. and LANGMANN, T. (2010). Microglia in the healthy and degenerating retina: insights from novel mouse models. Immunobiology 215: 685-691.

KENNAN, A., AHERNE, A. and HUMPHRIES, P. (2005). Light in retinitis pigmentosa. Trends Genet 21: 103-110.

KOMEIMA, K., ROGERS, B.S. and CAMPOCHIARO, P.A. (2007). Antioxidants slow photoreceptor cell death in mouse models of retinitis pigmentosa. J Cell Physiol 213: 809-815

KREUTZBERG, G.W. (1996). Microglia: a sensor for pathological events in the CNS. Trends Neurosci 19: 312-318.

LAI, A.Y. and TODD, K.G. (2008). Differential regulation of trophic and proinflammatory microglial effectors is dependent on severity of neuronal injury. Glia 56: 259-270.

LANGMANN, T. (2007). Microglia activation in retinal degeneration. J Leukoc Biol 81: $1345-1351$

LEWIS, G.P. and FISHER, S.K. (2003). Up-regulation of glial fibrillary acidic protein in response to retinal injury: its potential role in glial remodeling and a comparison to vimentin expression. Int Rev Cytol 230: 263-290.

MASLAND, R.H. (2001). The fundamental plan of the retina. Nat Neurosci4: 877-886. MASLAND, R.H. (2012a). The neuronal organization of the retina. Neuron76:266-280. MASLAND, R.H. (2012b). The tasks of amacrine cells. Vis Neurosci 29: 3-9.
NEWMAN, E. and REICHENBACH, A. (1996). The Muller cell: a functional element of the retina. Trends Neurosci 19: 307-312.

NOAILLES, A., FERNANDEZ-SANCHEZ, L., LAX, P. and CUENCA, N. (2014). Microglia activation in a model of retinal degeneration and TUDCA neuroprotective effects. J Neuroinflammation 11: 186.

OOTO, S., AKAGI, T., KAGEYAMA, R., AKITA, J., MANDAI, M., HONDA, Y. and TAKAHASHI, M. (2004). Potential for neural regeneration after neurotoxic injury in the adult mammalian retina. Proc Natl Acad Sci USA 101: 13654-13659.

PEKNY, M. and LANE, E.B. (2007). Intermediate filaments and stress. Exp Cell Res 313: $2244-2254$.

PEKNY, M. and NILSSON, M. (2005). Astrocyte activation and reactive gliosis. Glia 50: $427-434$

PENG, B., XIAO, J., WANG, K., SO, K.F., TIPOE, G.L. and LIN, B. (2014). Suppression of microglial activation is neuroprotective in a mouse model of human retinitis pigmentosa. J Neurosci 34: 8139-8150.

PENNESI, M.E., MICHAELS, K.V., MAGEE, S.S., MARICLE, A., DAVIN, S.P., GARG, A.K., GALE, M.J., TU, D.C., WEN, Y., ERKER, L.R. et al., (2012). Long-term characterization of retinal degeneration in rd1 and rd10 mice using spectra domain optical coherence tomography. Invest Ophthalmol Vis Sci 53: 4644-4656.

PITTLER, S.J. and BAEHR, W. (1991). Identification of a nonsense mutation in the rod photoreceptor cGMP phosphodiesterase beta-subunit gene of the rd mouse. Proc Natl Acad Sci USA 88: 8322-8326.

PUTHUSSERY, T., GAYET-PRIMO, J., PANDEY, S., DUVOISIN, R.M. and TAYLOR, W.R. (2009). Differential loss and preservation of glutamate receptor function in bipolar cells in the rd10 mouse model of retinitis pigmentosa. Eur $\mathrm{J} \mathrm{Neurosci}$ 29: 1533-1542.

RODRIGUEZ-MUELA, N., HERNANDEZ-PINTO, A.M., SERRANO-PUEBLA, A. GARCIA-LEDO, L., LATORRE, S.H., DE LA ROSA, E.J. and BOYA, P. (2015) Lysosomal membrane permeabilization and autophagy blockade contribute to photoreceptor cell death in a mouse model of retinitis pigmentosa. Cell Death Differ 22: 476-487.

ROQUE, R.S., IMPERIAL, C.J. and CALDWELL, R.B. (1996). Microglial cells invade the outer retina as photoreceptors degenerate in Royal College of Surgeons rats. Invest Ophthalmol Vis Sci 37: 196-203.

ROQUE, R.S., ROSALES, A.A., JINGJING, L., AGARWAL, N. and AL-UBAIDI, M.R (1999). Retina-derived microglial cells induce photoreceptor cell death in vitro. Brain Res 836: 110-119.

SAMARDZIJA, M., WARIWODA, H., IMSAND, C., HUBER, P., HEYNEN, S.R., GUBLER, A. and GRIMM, C. (2012). Activation of survival pathways in the degenerating retina of rd10 mice. Exp Eye Res 99: 17-26

SANTOS, A.M., CALVENTE, R., TASSI, M., CARRASCO, M.C., MARTIN-OLIVA, D. MARIN-TEVA, J.L., NAVASCUES, J. and CUADROS, M.A. (2008). Embryonic and postnatal development of microglial cells in the mouse retina. J Comp Neurol 506: 224-239

SANTOS, A.M., MARTIN-OLIVA, D., FERRER-MARTIN, R.M., TASSI, M., CALVENTE, R., SIERRA, A., CARRASCO, M.C., MARIN-TEVA, J.L., NAVASCUES, J. and CUADROS, M.A. (2010). Microglial response to light-induced photoreceptor degeneration in the mouse retina. J Comp Neurol 518: 477-492.

SANYAL, S. and BAL, A.K. (1973). Comparative light and electron microscopic study of retinal histogenesis in normal and rd mutant mice. Z Anat Entwicklungsgesch 142: $219-238$

SASAHARA, M., OTANI, A., OISHI, A., KOJIMA, H., YODOI, Y., KAMEDA, T., NAKAMURA, $\mathrm{H}$. and YOSHIMURA, N. (2008). Activation of bone marrow-derived microglia promotes photoreceptor survival in inherited retinal degeneration. $A m$ J Pathol 172: 1693-1703.

SINGHAL, S., BHATIA, B., JAYARAM, H., BECKER, S., JONES, M.F., COTTRILL, P.B., KHAW, P.T., SALT, T.E. and LIMB, G.A. (2012). Human Muller glia with stem cell characteristics differentiate into retinal ganglion cell (RGC) precursors in vitro and partially restore RGC function in vivo following transplantation. Stem Cells Transl Med 1: 188-199.

THANOS, S. (1992). Sick photoreceptors attract activated microglia from the ganglion cell layer: a model to study the inflammatory cascades in rats with inherited retina dystrophy. Brain Res 588: 21-28.

UREN, P.J., LEE, J.T., DOROUDCHI, M.M., SMITH, A.D. and HORSAGER, A. (2014). A profile of transcriptomic changes in the rd10 mouse model of retinitis pigmentosa. Mol Vis 20: 1612-1628. 
VECINO, E., RODRIGUEZ, F.D., RUZAFA, N., PEREIRO, X. and SHARMA, S.C. (2016). Glia-neuron interactions in the mammalian retina. Prog Retin Eye Res 51: 1-40.

WANG, M., MA, W., ZHAO, L., FARISS, R.N. and WONG, W.T. (2011). Adaptive Muller cell responses to microglial activation mediate neuroprotection and coordinate inflammation in the retina. $J$ Neuroinflammation 8: 173.

WANG, M., WANG, X., ZHAO, L., MA, W., RODRIGUEZ, I.R., FARISS, R.N. and WONG, W.T. (2014). Macroglia-microglia interactions via TSPO signaling regulates microglial activation in the mouse retina. J Neurosci 34: 3793-3806.

WELLARD, J., LEE, D., VALTER, K. and STONE, J. (2005). Photoreceptors in the rat retina are specifically vulnerable to both hypoxia and hyperoxia. Vis Neurosci 22: 501-507.

WYSE JACKSON, A.C. and COTTER, T.G. (2016). The synthetic progesterone Norgestrel is neuroprotective in stressed photoreceptor-like cells and retinal explants, mediating its effects via basic fibroblast growth factor, protein kinase A and glycogen synthase kinase 3beta signalling. Eur $J$ Neurosci 43: 899-911.

WYSE JACKSON, A.C., ROCHE, S.L., BYRNE, A.M., RUIZ-LOPEZ, A.M. and COTTER, T.G. (2016). Progesterone receptor signalling in retinal photoreceptor neuroprotection. J Neurochem 136: 63-77.
XUE, L.P., LU, J., CAO, Q., HU, S., DING, P. and LING, E.A. (2006). Muller glial cells express nestin coupled with glial fibrillary acidic protein in experimentally induced glaucoma in the rat retina. Neuroscience 139: 723-732.

YOSHIDA, N., IKEDA, Y., NOTOMI, S., ISHIKAWA, K., MURAKAMI, Y., HISATOMI, T., ENAIDA, H. and ISHIBASHI, T. (2013). Laboratory evidence of sustained chronic inflammatory reaction in retinitis pigmentosa. Ophthalmology 120: e5-12.

ZENG, H., DING, M., CHEN, X.X. and LU, Q. (2014). Microglial NADPH oxidase activation mediates rod cell death in the retinal degeneration in rd mice. Neuroscience 275: 54-61.

ZENG, H.Y., ZHU, X.A., ZHANG, C., YANG, L.P., WU, L.M. and TSO, M.O. (2005). Identification of sequential events and factors associated with microglial activation, migration, and cytotoxicity in retinal degeneration in rd mice. Invest Ophthalmol Vis Sci 46: 2992-2999.

ZHAO, L., ZABEL, M.K., WANG, X., MA, W., SHAH, P., FARISS, R.N., QIAN, H., PARKHURST, C.N., GAN, W.B. and WONG, W.T. (2015). Microglial phagocytosis of living photoreceptors contributes to inherited retinal degeneration. EMBO MOI Med 7: 1179-1197. 


\section{Further Related Reading, published previously in the Int. J. Dev. Biol.}

Microarchitectural changes during development of the cerebellar cortex

Miriam Mecha, Angel L. Peña-Melián and Maria J. Blanco

Int. J. Dev. Biol. (2010) 54: 691-698

http://dx.doi.org/10.1387/ijdb.082670mm

Early neural cell death: numbers and cues from the developing neuroretina

Ana I. Valenciano, Patricia Boya and Enrique J. de la Rosa

Int. J. Dev. Biol. (2009) 53: 1515-1528

http://dx.doi.org/10.1387/ijdb.072446av

Key apoptosis regulating proteins are down-regulated during postnatal tissue development

Shane D. Madden, Maryanne Donovan and Thomas G. Cotter

Int. J. Dev. Biol. (2007) 51: 415-424

http://dx.doi.org/10.1387/ijdb.062263sm

Genetics of photoreceptor development and function in zebrafish

Motokazu Tsujikawa and Jarema Malicki

Int. J. Dev. Biol. (2004) 48: 925-934

http://dx.doi.org/10.1387/ijdb.041890mt

Analysis of mouse eye development with chimeras and mosaics

J. Martin Collinson, Robert E. Hill and John D. West

Int. J. Dev. Biol. (2004) 48: 793-804

http://dx.doi.org/10.1387/ijdb.041885jc

5 yr ISI Impact Factor $(2013)=2.879$
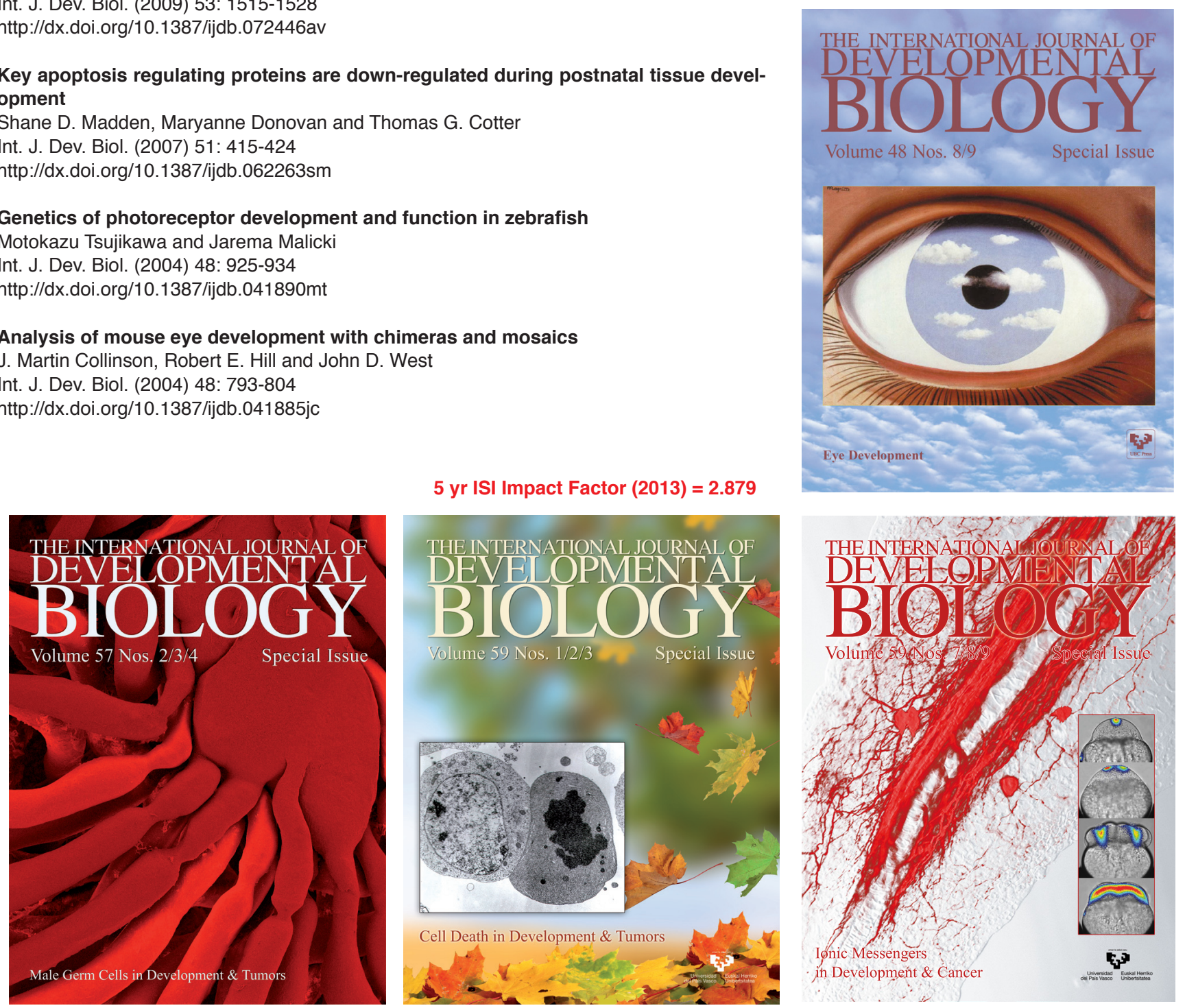